\title{
Thermal Reactor Model for Large-Scale Algae Cultivation in Vertical Flat Panel Photobioreactors - SUPPORTING INFORMATION
}

\author{
Christian H. Endres*, Arne Roth, Thomas B. Brück
}

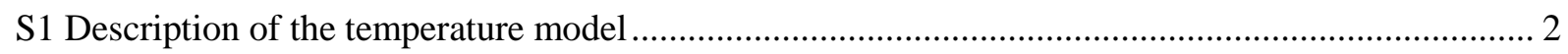

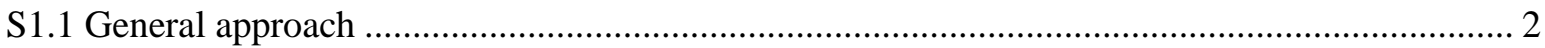

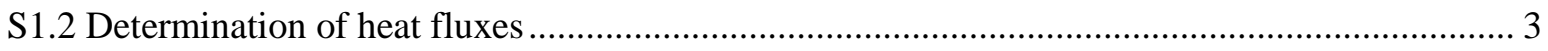

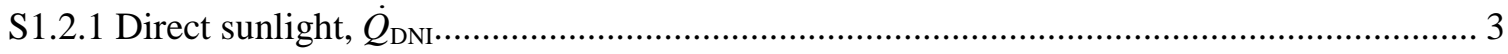

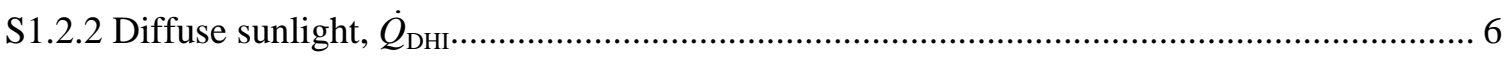

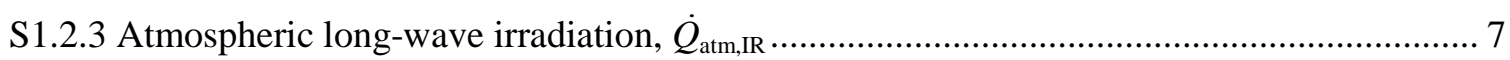

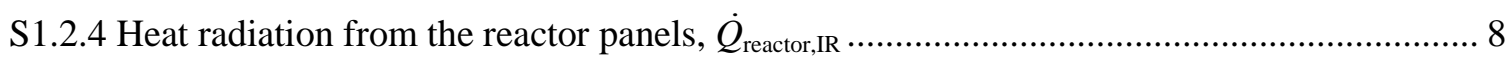

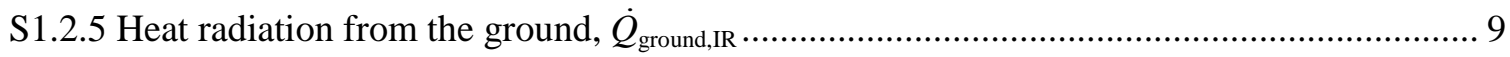

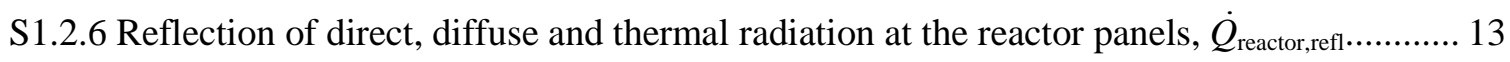

S1.2.7 Reflection of direct, diffuse and thermal radiation at the ground, $\dot{Q}_{\text {ground,refl }} \ldots \ldots \ldots \ldots \ldots \ldots . . . . . . . . . .18$

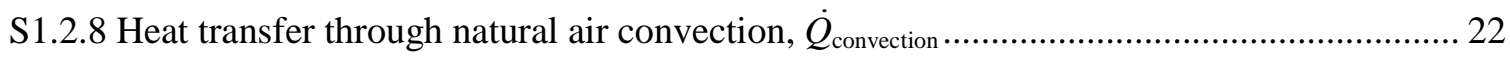

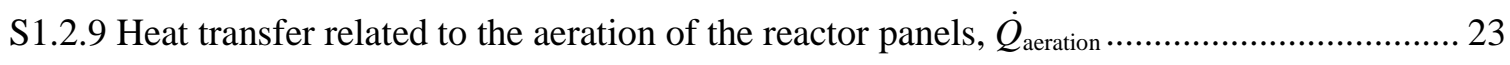

S2 Supplementary temperature simulations and related content ........................................................ 27

S2.1 Influence of the reactor height on the temperature profile assuming a constant ratio between

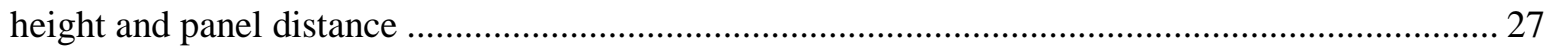

S2.2 Impact of the biomass fixation rate and the albedo of the culture medium on the outcome of the

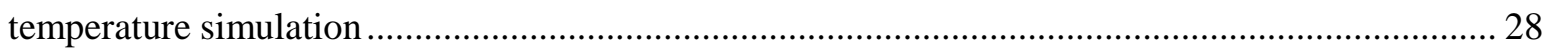

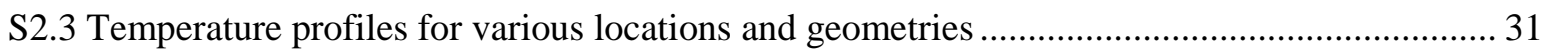

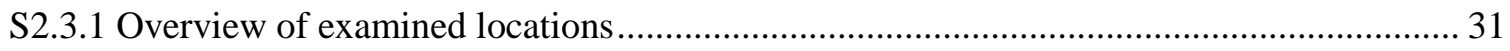

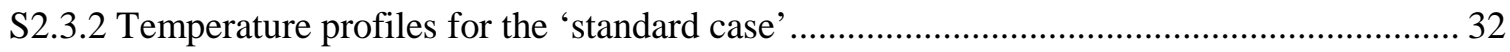

S2.3.3 Temperature profiles for reactors facing in east-west direction ....................................... 33

S2.3.4 Temperature profiles for an increased panel distance …..................................................... 34

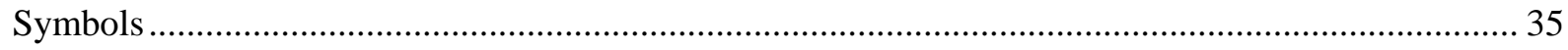

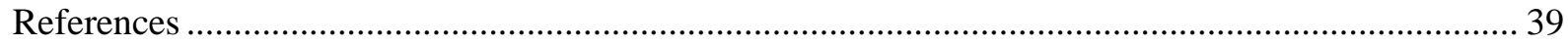

Nr. Figures: 12

Nr. Tables: 6

Nr. Pages: 40 


\section{S1 Description of the temperature model}

\section{S1.1 General approach}

To simulate the temperature within the vertical flat panel photobioreactors a MATLAB model (The MathWorks, Inc., Natick, MA) was developed. This model is described in the following.

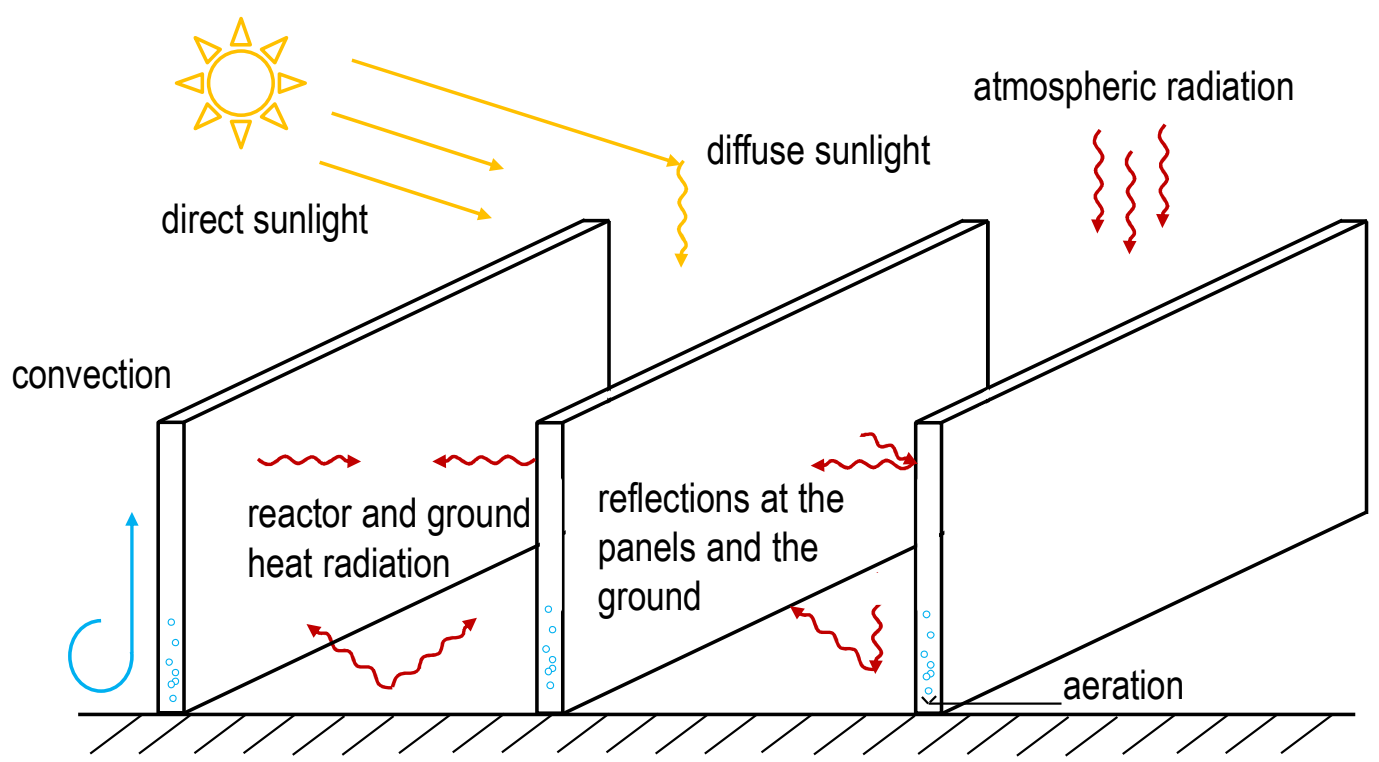

Figure S1. Schematic illustration of the flat plate photobioreactor plant-setup and the heat fluxes considered for temperature simulation.

The model is based on a heat balance of the relevant heat fluxes affecting the reactor (Figure S1). From the sum of the individual heat fluxes the change of the reactor temperature, $\Delta T_{\mathrm{R}}$ (Equation S1) can be calculated. As starting condition, a reactor temperature of $20{ }^{\circ} \mathrm{C}$ is chosen. Subsequently the reactor temperature is updated every minute based on the abovementioned heat balance. To simulate the reactor temperature of a complete year, 525601 data points are generated. 


$$
\begin{aligned}
V_{\mathrm{R}} \rho_{\mathrm{R}} c_{P \mathrm{R}} \Delta T_{\mathrm{R}}= & \left(\dot{Q}_{\mathrm{DNI}}+\dot{Q}_{\mathrm{DHI}}+\dot{Q}_{\mathrm{atm}, \mathrm{IR}}+\dot{Q}_{\text {reactor,IR }}+\dot{Q}_{\text {ground, IR }}+\dot{Q}_{\text {ground,refl }}\right. \\
& \left.+\dot{Q}_{\text {reactor,refl }}+\dot{Q}_{\text {convection }}+\dot{Q}_{\text {aeration }}\right) \Delta t
\end{aligned}
$$

$V_{\mathrm{R}}$ is the volume of the reactor; $\rho_{\mathrm{R}}$ and $c_{P \mathrm{R}}$ are the density and the specific heat capacity of the culture medium. On the right hand side of the equation, the heat fluxes affecting the reactor are displayed. $\dot{Q}_{\mathrm{DNI}}$ and $\dot{Q}_{\mathrm{DHI}}$ are the heat fluxes related to the direct and indirect irradiation of sunlight. $\dot{Q}_{\text {atm,IR }}, \dot{Q}_{\text {reactor,IR }}$ and $\dot{Q}_{\text {ground,IR }}$ is the heat radiation of the atmosphere, the reactor and the ground, respectively. $\dot{Q}_{\text {ground,refl }}$ is the sum of all radiative heat fluxes that are reflected by the ground's surface and received by one of the panels. Analogous, $\dot{Q}_{\text {reactor,ref }}$ is the sum of all radiative heat fluxes reflected by the reactor panels and received by an opposing panel. $\dot{Q}_{\text {convection }}$ represents the heat exchange of the reactor with the surrounding air via convection. Heat loss related to the aeration of the photobioreactors is described by $\dot{Q}_{\text {aeration. }} \Delta t$ is the time interval between two datapoints. Rainfall and condensation of water at the reactor panels and the ground are not covered by the model.

In the following, the calculation of the individual heat fluxes is further described.

\section{S1.2 Determination of heat fluxes}

\section{S1.2.1 Direct sunlight, $\dot{Q}_{\mathrm{DNI}}$}

The heat flux resulting from irradiation of direct sunlight is given by:

$$
\dot{Q}_{\mathrm{DNI}}=\left(1-\alpha_{\mathrm{alb}, \mathrm{R}}\right) \tau_{\mathrm{dir}, \mathrm{in}} A_{\mathrm{R}}^{\prime} I_{\mathrm{R}, \mathrm{DNI}}-\dot{Q}_{\mathrm{bio}, \mathrm{DNI}}
$$

$I_{\mathrm{R}, \mathrm{DNI}}$ is the intensity of incoming light related to a vertical plane, $A_{\mathrm{R}}$ ' is the area of the reactor that is exposed to direct sunlight, $\tau_{\mathrm{dir}, \text { in }}$ is the transmissivity of the reactor casing for direct 
incoming light calculated from the Fresnel equations and $\alpha_{\mathrm{alb}, \mathrm{R}}$ is the albedo of the culture medium. The albedo is defined as the fraction of incident sunlight that is not absorbed but reflected by a certain surface. For our model we assume an albedo of 0.3 as being representative for the algae medium, which is a typical value for thick plant leaves ${ }^{1}$ (see also Section S2.2). $\dot{Q}_{\text {bio,DNI }}$ is the fraction of light that is converted into biomass and thus does not contribute to heating up the reactor. In this context it is important to note that algae only convert radiation in the visible spectrum of light into chemical energy. Thermal radiation cannot be used for biomass generation via photosynthesis.

$I_{\mathrm{R}, \mathrm{DNI}}$ can be easily calculated from the intensity of the direct light on a horizontal plane, $I_{0, \mathrm{DNI}}$, and the angle of incidence, $\Theta$, by the following equation:

$$
I_{\mathrm{R}, \mathrm{DNI}}=\cos (\theta) \cdot I_{0, \mathrm{DNI}}
$$

To determine the angle of incidence, the solar altitude angle $\alpha$ and the solar azimuth angle $A$ must be known for each considered time step. Methods for calculating these angles as a function of time based on the longitude and latitude of a specific site were adopted from Stine and Geyer. ${ }^{2}$

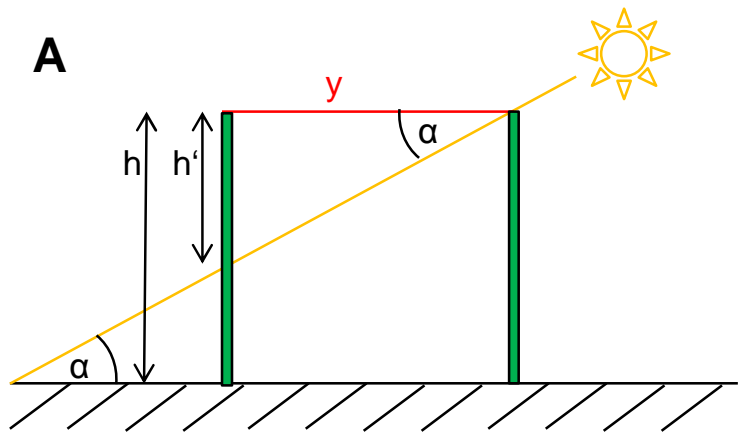

B

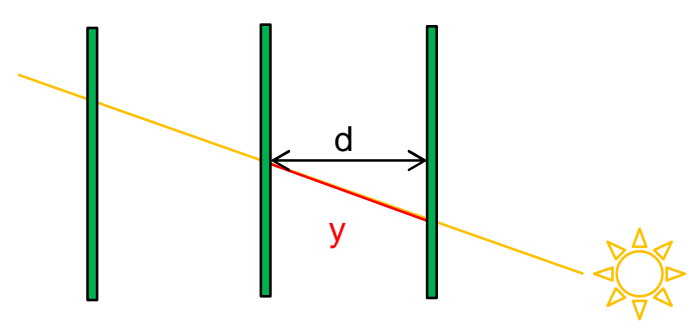

Figure S2. Illuminated and shaded areas of the reactor panels: (A) view from the side, (B) view from the top. 
The reactor surface can be divided into two parts: the upper part is exposed to direct sunlight while the lower part of the reactor is shaded. For our calculation we follow the method described by Slegers et al. ${ }^{3}$ As can be seen from the scheme displayed in Figure S2, the irradiated part of the reactor surface can be calculated from:

$$
A_{\mathrm{R}}^{\prime}=A_{\mathrm{R}} \frac{h^{\prime}}{h}
$$

$A_{R}$ is the total reactor surface (one side) and $h$ is the height of the reactor. $h$ ' is the distance between the top of the reactor and the upper edge of the shade and is given by

$$
h^{\prime}=\frac{\tan (\alpha)}{y}=\frac{d \cdot \tan (\alpha)}{|\cos (\gamma-A)|}
$$

where $d$ is the distance between the panel rows and $\gamma$ is the orientation of the reactor panels (aperture azimuth angle). ${ }^{2,3}$ For the azimuth angles $A$ and $\gamma$ the north direction is assumed zero and angles in clockwise directions are counted positive.

As a detailed growth model for algae biomass has not been implemented in the model at the time of publication, only a simple approximation was applied to take algae growth into consideration. It is assumed that $1.5 \%$ of the sunlight (no IR-radiation) reaching the culture medium is absorbed by the algae and converted into chemical energy. For a comparison, rapidly growing trees, such as poplars, only reach values of around $1 \%{ }^{4} \dot{Q}_{\text {bio,DNI }}$ can thus be expressed as

$$
\dot{Q}_{\mathrm{bio}, \mathrm{DNI}}=\tau_{\mathrm{dir}, \mathrm{in}} A_{\mathrm{R}}^{\prime} I_{\mathrm{R}, \mathrm{DNI}} \cdot X_{\mathrm{bio}}
$$


where $X_{\mathrm{bio}}$ is the above mentioned biomass fixation rate of $1.5 \%$ (for a sensitivity analysis of the biomass fixation rate, please refer to Section 2.2)

\section{S1.2.2 Diffuse sunlight, $\dot{Q}_{\mathrm{DHI}}$}

In addition to direct irradiation, reactor panels are also exposed to diffuse sunlight. From the view of the panels, diffuse light is emitted by a rectangular area between the panel rows (the opening to the sky). The fraction of light leaving this area and reaching the reactor surfaces can be expressed by so-called configuration factors. The configuration factor used for the just mentioned geometry, $F_{1}$, as well as further configuration factors discussed later in the document are calculated from equations given in Kabelac et al. $^{5}$ and Howel ${ }^{6}$ (see also Figure S12 at the end of this document for an overview of all viewing factors). The heat flux from diffuse light is described by the following equation. Please note that both, the front and the back, of the panel are exposed to diffuse light and therefore a factor of 2 is required in the equation.

$$
\dot{Q}_{\mathrm{DHI}}=2\left(1-\alpha_{\mathrm{alb}, \mathrm{R}}\right) \tau_{\mathrm{dif,in}} F_{1} l d I_{0, \mathrm{DHI}}-\dot{Q}_{\mathrm{bio}, \mathrm{DHI}}
$$

The length of a single panel is described by the variable $l$ and $\tau_{\text {diff,in }}$ is the transmittance of the reactor wall for diffuse radiation. As no definite angle can be attributed to diffuse radiation, an integrative value of the transmittance is determined for angles ranging from $0^{\circ}$ to $90^{\circ}$. The fraction of incoming diffuse sunlight that is converted into biomass, $\dot{Q}_{\text {bio,DHI }}$, can be calculated according to the following equation:

$$
\dot{Q}_{\mathrm{bio}, \mathrm{DHI}}=2 \tau_{\mathrm{dif}, \mathrm{in}} F_{1} l d I_{0, \mathrm{DHI}} \cdot X_{\mathrm{bio}}
$$




\section{S1.2.3 Atmospheric long-wave irradiation, $\dot{Q}_{\mathrm{atm}, \mathrm{IR}}$}

The atmosphere emits thermal radiation that contributes to the heat balance of the reactor. This heat flux can be described by:

$$
\dot{Q}_{\mathrm{atm}, \mathrm{IR}}=\varepsilon_{\mathrm{R}} F_{1} 2 l d I_{\mathrm{sky}, \mathrm{IR}}
$$

For infrared radiation it is assumed that the absorptivity of the reactor equals its emissivity, $\varepsilon_{\mathrm{R}}$. The albedo is not used for thermal radiation as it is generally defined for the spectrum of visible light (sunlight), not for the far infrared. Glass has a high emissivity and therefore the majority of thermal radiation is absorbed by the reactor wall rather than by the culture medium. The fraction of light transmitted to the culture medium and absorbed by the water body is therefore neglected in the model. Furthermore, the temperature of the reactor wall and the culture medium are considered equal, as it is assumed that heat exchange between the wall and the reactor is very efficient due to the high turbulence caused by the aeration of the reactors.

In contrast to a glass plane, thin films made of polyethylene (PE) only absorb a small fraction of incoming infrared irradiation. However, as the culture medium itself has a very high absorptivity of infrared radiation, the results of the model can to some degree be transferred to flat bag reactors made of PE.

The atmosphere is a thermal radiator. Therefore the intensity of radiation emitted by the atmosphere, $I_{\text {sky,IR }}$, can be expressed by the Stefan-Boltzmann law:

$$
I_{\mathrm{sky}, \mathrm{IR}}=\varepsilon_{\mathrm{atm}} \sigma T_{\mathrm{air}}^{4}
$$


The gray-body emissivity of the atmosphere, $\varepsilon_{\mathrm{atm}}$, can be calculated from meteorological parameter-based methods. For the temperature model presented in this work, the widely accepted Brutsaert equation ${ }^{7}$ is used in combination with the cloud cover model of Crawford and Duchon ${ }^{8}$. As demonstrated by Wang and Liang $^{9}$, this combination works well for a large variety of climatic conditions and is therefore applied to the different locations examined in this work.

$$
\varepsilon_{\mathrm{atm}}=c+(1-c)\left[1.24\left(\frac{\frac{e_{\mathrm{w}}}{1 \mathrm{mbar}}}{\frac{T_{\mathrm{air}}-273.15 \mathrm{~K}}{1 \mathrm{~K}}}\right)^{\frac{1}{7}}\right]
$$

$c$ is the fraction of the sky covered by clouds and $e_{\mathrm{w}}$ is the water vapor pressure of the surrounding air. The water vapor pressure is calculated with the Arden-Buck equation ${ }^{10}$ (not shown).

\section{S1.2.4 Heat radiation from the reactor panels, $\dot{Q}_{\text {reactor,IR }}$}

The reactor loses thermal energy by emitting infrared radiation (Equation S12, negative term on the right). At the same time a certain amount of that energy is taken up again from opposing reactor panels, as they are also emitting light that reaches the original reactor (Equation 12, positive term on the right). The total heat flux for reactor radiation is therefore defined as

$$
\dot{Q}_{\text {reactor,IR }}=-2 \varepsilon_{\mathrm{R}} h l \sigma T_{\mathrm{R}}^{4}+2 \varepsilon_{R} F_{2} \tau \varepsilon_{\mathrm{R}} \sigma h l T_{\mathrm{R}}^{4},
$$

where $F_{2}$ is the configuration factor for opposing reactor panels and $T_{\mathrm{R}}$ is the temperature of the photobioreactor. 


\section{S1.2.5 Heat radiation from the ground, $\dot{Q}_{\text {ground,IR }}$}

In the same way as the reactor and the atmosphere, also the ground emits thermal radiation.

The infrared radiation of the ground can thus be described by the Stefan-Boltzmann law:

$$
\dot{Q}_{\text {ground,IR }}=2 \varepsilon_{\mathrm{R}} \tau F_{1} \varepsilon_{\mathrm{G}} \sigma l d T_{\mathrm{G}}^{4}
$$

The emissivity of the ground, $\varepsilon_{\mathrm{G}}$, is assumed with a value of 0.95 , which is in good accordance with many soil types without vegetation. ${ }^{11}$ The configuration factor between the ground and the reactor panels, $F_{1}$, is identical to the configuration factor between the opening to the sky and the panels (see Section S1.2.2). As the temperature of the top layer of the ground, $T_{\mathrm{G}}$, is not part of the TMY3-Dataset ${ }^{12}$, a multilayer ground model is used for the calculation of $T_{\mathrm{G}}$. This model is further described in the following.

The top layer of the ground is exposed to the atmosphere and therefore this layer exchanges heat with the surrounding environment. Additionally, all ground layers exchange heat with neighboring ground layers via heat conduction.

Daily and seasonal temperature fluctuations are most pronounced in the first centimeters of the soil. With increasing depth, these fluctuation become less distinct and from a depth of $16.4 \mathrm{~m}$ onwards ground temperature is considered constant during the whole year. ${ }^{13,14}$ For the model, the ground is discretized in 13 layers of varying thicknesses. The first layer is $2 \mathrm{~mm}$ thick and thickness doubles with every further layer (Table S1). This exponential growth is chosen in order to adequately display temperature fluctuations near the top, while at the same time saving computation time at greater soil depths, where temperature gradients are less distinct.

A total of five iterations is performed to allow the ground layers to adjust to the correct temperature according to the heat balance. As starting condition for the first iteration, the top layer temperature, $T_{0}$, is chosen identical to the air temperature, while the temperature of the 
deepest layer, $T_{13}$, is assumed to equal to the temperature of shallow ground water. Values for ground water temperatures are taken from Heath ${ }^{15}$ and Druecker and Fan ${ }^{16}$ for territorial US and Hawaii, respectively. An overview of the considered ground water temperatures at the locations examined in the publication can be found in Table S4 (Section S2.3.1). Starting temperatures of intermediate layers are determined by linear interpolation.

For every further iteration, the temperature profile $\left(T_{0}\right.$ to $\left.T_{12}\right)$ of the previous iteration of the last time step in December is used as new stating condition. The temperature of the deepest layer is determined as yearly average of $T_{0}$ of the previous year. It was observed that after five iterations deviation in temperature from one iteration to the next is less than $1 \%$.

Table S1. Composition of the multilayer ground model.

\begin{tabular}{llll}
\hline node $\mathrm{nr}$. & $\begin{array}{l}\text { distance to } \\
\text { next node, } \Delta \mathrm{x}\end{array}$ & depth at node & starting temperature \\
\hline 0 & $0.002 \mathrm{~m}$ & $0 \mathrm{~m}$ & $T_{0}=T_{\mathrm{G}}=T_{\text {air }}$ \\
1 & $0.004 \mathrm{~m}$ & $0.002 \mathrm{~m}$ & lin. interpolation \\
2 & $0.008 \mathrm{~m}$ & $0.006 \mathrm{~m}$ & lin. interpolation \\
3 & $0.016 \mathrm{~m}$ & $0.014 \mathrm{~m}$ & lin. interpolation \\
4 & $0.032 \mathrm{~m}$ & $0.030 \mathrm{~m}$ & lin. interpolation \\
5 & $0.064 \mathrm{~m}$ & $0.062 \mathrm{~m}$ & lin. interpolation \\
6 & $0.128 \mathrm{~m}$ & $0.126 \mathrm{~m}$ & lin. interpolation \\
7 & $0.256 \mathrm{~m}$ & $0.254 \mathrm{~m}$ & lin. interpolation \\
8 & $0.512 \mathrm{~m}$ & $0.510 \mathrm{~m}$ & lin. interpolation \\
9 & $1.024 \mathrm{~m}$ & $1.022 \mathrm{~m}$ & lin. interpolation \\
10 & $2.048 \mathrm{~m}$ & $2.046 \mathrm{~m}$ & lin. interpolation \\
11 & $4.096 \mathrm{~m}$ & $4.094 \mathrm{~m}$ & lin. interpolation \\
12 & $8.192 \mathrm{~m}$ & $8.190 \mathrm{~m}$ & lin. interpolation \\
13 & $\infty$ & $16.382 \mathrm{~m}$ & $T_{13}=T_{\text {ground }}$ \\
\hline
\end{tabular}

The calculation of the ground temperature at different depths is based on Cengel and Ghajar ${ }^{17}$ using the definitions given the Figure S3. 


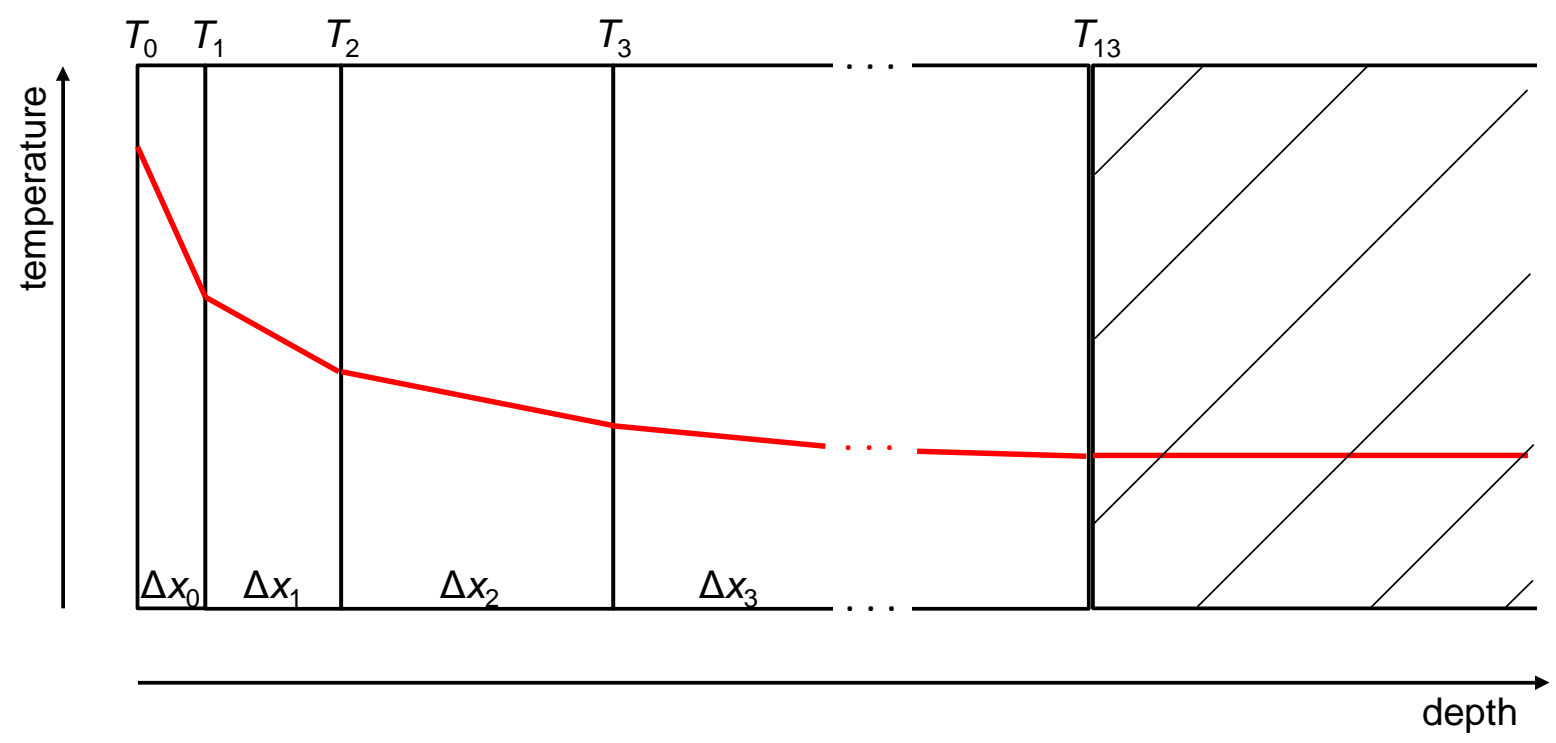

Figure S3. Graphical illustration of the ground model; red line indicates a typical ground temperature profile during a warm day.

The temperature $T_{\mathrm{G}}$ ( $T_{0}$ in the figure) at the very top is calculated according to the following equation:

$$
\sum_{i} \dot{Q}_{i, \text { external }}+\frac{k_{\mathrm{G}} l d}{\Delta x_{0}}\left(T^{\prime}{ }_{1}-T_{\mathrm{G}}^{\prime}\right)=l d \frac{\Delta x_{0}}{2} c_{P, V}\left(T_{\mathrm{G}}-T_{\mathrm{G}}^{\prime}\right)
$$

$\sum_{i} \dot{Q}_{i, \text { external }}$ is the sum of external heat fluxes affecting the top ground layer. The calculation of these heat fluxes is not shown here, however, it follows the same principles as the calculation of the heat fluxes affecting the reactor panels. First order reflections from the panels to the ground are considered for the ground as well. The heat conductivity of the soil, $k_{\mathrm{G}}$, and the volumetric heat capacity, $c_{\mathrm{P}, \mathrm{V}}$, is assumed with $0.5 \mathrm{~W} \mathrm{~m}^{-1} \mathrm{~K}^{-1}$ and $1.5 \cdot 10^{6} \mathrm{~J} \mathrm{~m}^{-3} \mathrm{~K}^{-1}$, respectively. Both values correspond to slightly humid loamy sandy soils without any vegetation. ${ }^{11} T_{1}$ is the temperature at the interface between the top surface layer and the proceeding layer. The apostrophes at the temperature variables indicate that the values of the 
previous time step are used. As can be seen from Figure S3, $\Delta x_{0}$ is the thickness of the top ground layer.

Intermediate layers are not exposed to the atmosphere. Therefore heat transfer occurs only via heat conduction. The temperature, $T_{n}$, at the interface between layer $n$ and layer $n-1$ is calculated according to the following equation:

$$
\frac{k_{\mathrm{G}} l d}{\Delta x_{n-1}}\left(T^{\prime}{ }_{n-1}-T^{\prime}{ }_{n}\right)+\frac{k_{\mathrm{G}} l d}{\Delta x_{n}}\left(T^{\prime}{ }_{n+1}-T^{\prime}{ }_{n}\right)=l d \frac{\Delta x_{n-1}+\Delta x_{n}}{2} c_{P, V}\left(T_{n}-T^{\prime}{ }_{n}\right)
$$

By using the equations above, the temperatures for various depths are calculated. Figure S4 shows the temperature profile at the exemplary site of Sacramento. The reactor panel distance and panel thickness is set to $0.5 \mathrm{~m}$ and $0.05 \mathrm{~m}$, respectively. The orientation of the panels is in in north-south direction. As can be seen from Figure S4, the temperature near the surface area shows strong daily fluctuations with maximum temperatures reaching $60{ }^{\circ} \mathrm{C}$. With increasing depth daily fluctuations diminish and only seasonal temperature variations remain visible. Maximum temperatures for the top soil layers are typically reached during summer, while in lower layers the peak shifts towards the end of the year. This effect is a result of the soil's capability to store thermal energy. The described behavior of the ground temperature is in good accordance with soil temperature measurements described in the literature. ${ }^{13,14} \mathrm{We}$ therefore believe, that the soil temperature model used for the publication is a valuable tool to determine heat radiation from the ground. 


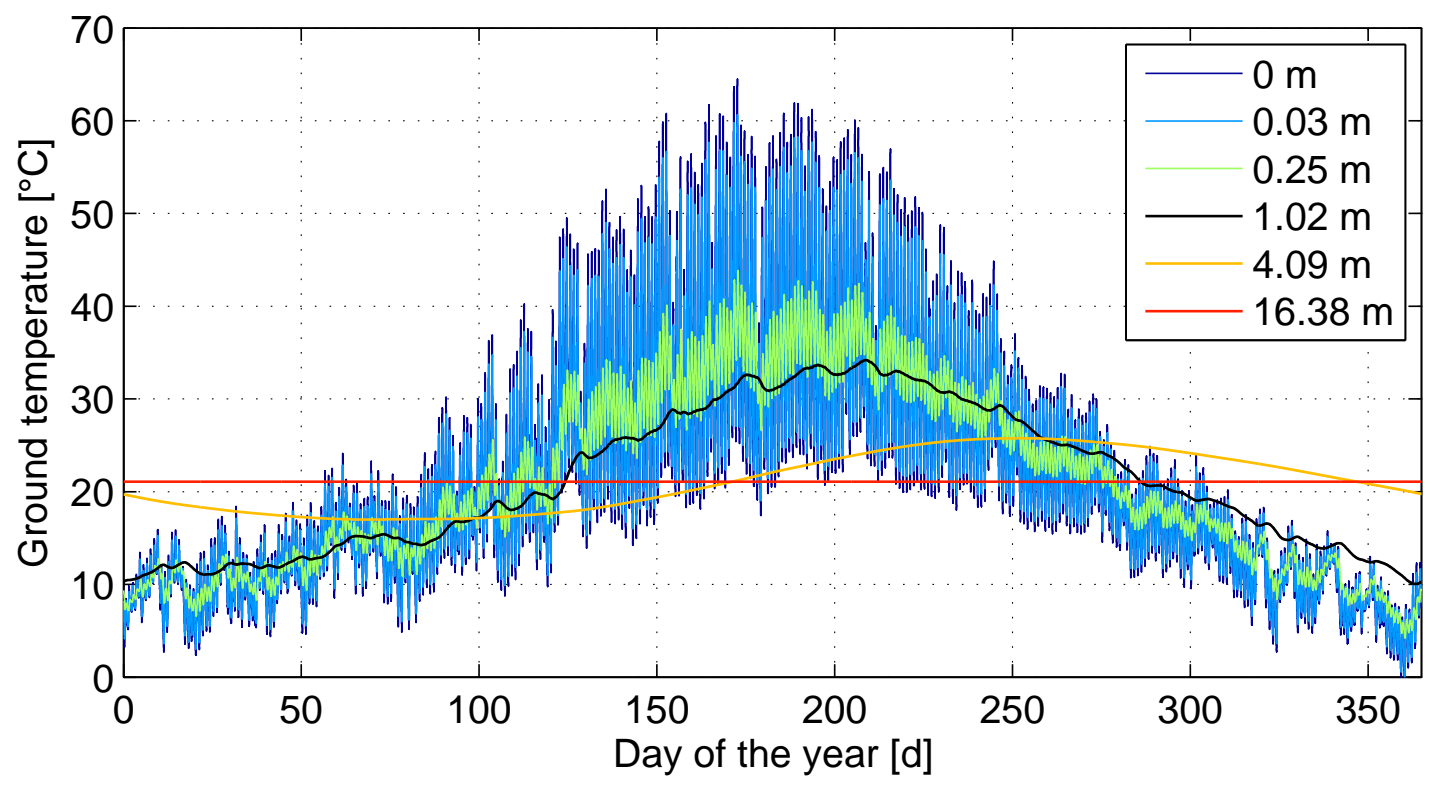

Figure S4. Temporal ground temperatures profiles at various depths simulated with the multilayer ground temperature model. (location, Sacramento, CA; panel distance, $0.5 \mathrm{~m}$; panel thickness, $0.05 \mathrm{~m}$; orientation, north-south)

\section{S1.2.6 Reflection of direct, diffuse and thermal radiation at the reactor panels, $\dot{Q}_{\text {reactor,refl }}$}

In this section radiation reflected by the reactor panels and received by a neighboring panel is described $\left(\dot{Q}_{\text {reactor,refl })}\right.$.

$$
\dot{Q}_{\text {reactor,refl }}=\dot{Q}_{\mathrm{DNI}, \mathrm{R}-\mathrm{refl}}+\dot{Q}_{\mathrm{DHI}, \mathrm{R}-\mathrm{refl}}+\dot{Q}_{\mathrm{atm}, \mathrm{IR}, \mathrm{R}-\mathrm{refl}}+\dot{Q}_{\text {reactor,IR,R-refll }}+\dot{Q}_{\text {ground,IR,R-refll }}
$$

The single heat fluxes contributing to $\dot{Q}_{\text {reactor,refl }}$ are explained in the following.

\section{S1.2.6.1 Direct sunlight reflected by a panel and received by the opposing panel,}

\section{$\dot{Q}_{\text {DNI,R-refl }}$}

Direct sunlight is reflected by the reactor wall, $Q_{\mathrm{DNI}, \mathrm{R}-\mathrm{refl} \_1}$, and the culture medium behind that wall, $Q_{\mathrm{DNI}, \mathrm{R}-\mathrm{refl} \_2}$. The total heat flux for direct sunlight reflected at a panel and received 
by an opposing panel, $\dot{Q}_{\mathrm{DNI}, \mathrm{R}-\mathrm{refl},}$ is defined as the sum of these two heat fluxes. For reflections at the surface of the reactor wall, $\dot{Q}_{\text {DNI,R-refl_1 }}$, three cases can be distinguished (see Figure S5)
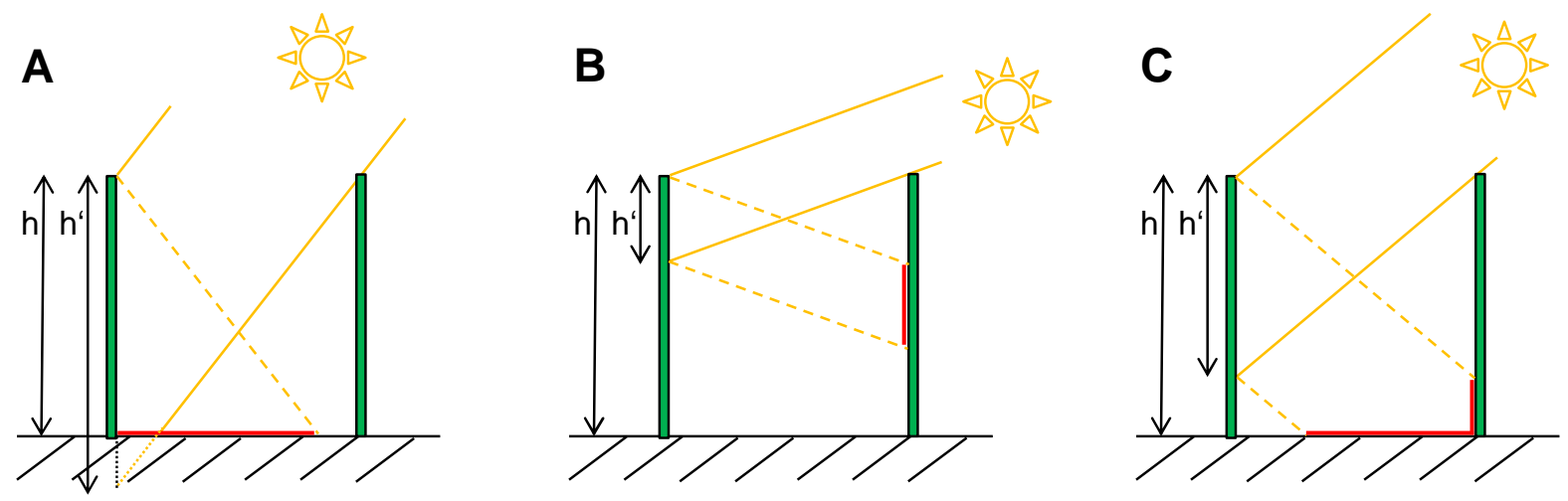

Figure S5. Reflections of direct sunlight at the reactor wall: (A) $h^{\prime} \geq h$ : all light is reflected to the ground; (B) $h^{\prime} \leq h / 2$ : all light is reflected to the opposing panel; (C) $h / 2<h^{\prime}<h$ : light is partially reflected to the ground and the opposing panel.

In case $\mathrm{A}$, light is reflected to the ground due to a large solar altitude angle. This case occurs when the projected height, $h$ ', is larger than the actual height of the panel. In contrary, in case $\mathrm{B}$, the solar altitude angle is small and thus all reflected light is received by the opposing panel. The premise for this case is that $h$ ' is smaller than half of the panel height. The last case represents an intermediate state between the cases A and B: One fraction of the reflected light hits the panel, while the rest is received by the ground. In this case $h$ ' has to be larger than half of the panel height, but smaller than the complete panel height.

Depending on the case, $\dot{Q}_{\text {DNI,R-refl_1 }}$ can be calculated with the following equations:

Case A: $h^{\prime} \geq h$

$$
\dot{Q}_{\text {DNI,R-refl_1 }}=0
$$


Case B: $h^{\prime} \leq \frac{h}{2}$

$$
\dot{Q}_{\mathrm{DNI}, \mathrm{R}-\text { refl_1 }}=\left(1-\alpha_{\mathrm{alb}, \mathrm{R}}\right) \tau(1-\tau) \cdot h^{\prime} l I_{\mathrm{R}, \mathrm{DNI}}-\dot{Q}_{\mathrm{bio}, \mathrm{DNI}, \mathrm{R}-\text { refl_1 }}
$$

Case C: $\frac{h}{2}<h^{\prime}<h$

$$
\dot{Q}_{\mathrm{DNI}, \mathrm{R}-\text { refl_1 }}=\left(1-\alpha_{\mathrm{alb}, \mathrm{R}}\right) \tau(1-\tau) \cdot\left(h-h^{\prime}\right) l I_{\mathrm{R}, \mathrm{DNI}}-\dot{Q}_{\mathrm{bio}, \mathrm{DNI}, \mathrm{R}-\text { refl_1 }}
$$

$\dot{Q}_{\text {bio,DNI,R-refl_1 }}$ is the fraction of $\dot{Q}_{\text {DNI,R-refl_1 }}$ that is converted by the algae into algae biomass. The calculation of $\dot{Q}_{\text {bio,DNI,R-refl_1 }}$ is analogous to the calculation of $\dot{Q}_{\text {bio,DNI }}$, which is described in Section S1.2.1.

Apart from reflections at the reactor wall, light can also be reflected from within the culture medium. The outgoing light is emitted in all directions of space. Thus, $\dot{Q}_{\text {DNI,R-refl_2 }}$ can be expressed as

$$
\dot{Q}_{\mathrm{DNI}, \mathrm{R}-\text { refl_2}}=\left(1-\alpha_{\mathrm{alb}, \mathrm{R}}\right) F_{3} \tau_{\mathrm{dif,out}} \alpha_{\mathrm{alb}, \mathrm{R}} \tau_{\mathrm{dir}, \mathrm{in}} \cdot h^{\prime} l I_{\mathrm{R}, \mathrm{DNI}}
$$

for $h^{\prime} \leq h$ and as

$$
\dot{Q}_{\mathrm{DNI}, \mathrm{R}-\mathrm{refl} \_2}=\left(1-\alpha_{\mathrm{alb}, \mathrm{R}}\right) F_{3} \tau_{\mathrm{dif}, \mathrm{out}} \alpha_{\mathrm{alb}, \mathrm{R}} \tau_{\mathrm{dir}, \mathrm{in}} \cdot h l I_{\mathrm{R}, \mathrm{DNI}}
$$

for $h^{\prime}>h$.

$\tau_{\text {diff,out }}$ is the transmittance of the reactor wall for diffuse radiation from within the reactor. Similar to $\tau_{\text {diff,in }}$, no definite angle can be attributed to the diffuse radiation and therefore, again, an integrative value of the transmittance is determined for angles ranging from $0^{\circ}$ to $90^{\circ} . F_{3}$ is the configuration factor for parallel planes, for the case that the light emitting area is smaller than the light receiving area. As can be seen from Equation 18, a term considering the accumulation of biomass is not included. The reason for this assumption is that algae are very 
sensitive to light in the photosynthetically active spectrum and will most likely absorb light of the corresponding wavelengths. We thus assume that the light, that is scattered back by the algae medium, will lack of these wavelengths and algae in the receiving reactor will therefore not be able to generate biomass from it.

\section{S1.2.6.2 Diffuse sunlight reflected by a panel and received by the opposing panel, $\dot{Q}_{\text {DHI,R-refl }}$}

Similar to direct light, diffuse sunlight is reflected both at the panel surface, $\dot{Q}_{\text {DHI,R-refl_1 }}$, and

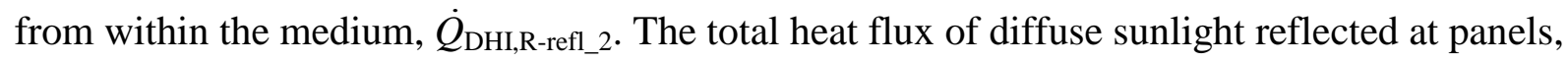
$\dot{Q}_{\text {DHI,R-refl, }}$ is the sum of $\dot{Q}_{\text {DHI,R-refl_1 }}$ and $\dot{Q}_{\text {DHI,R-refl_2. }}$

The reflections at the panel wall are calculated according to:

$$
\dot{Q}_{\text {DHI,R-refl_1 }}=2\left(1-\alpha_{\text {alb,R }}\right) \tau_{\text {dif,in }}\left(1-\tau_{\text {dif,in }}\right) F_{4} \cdot d l I_{0, \text { DHI }}-\dot{Q}_{\text {bio,DHI,R-refl_1 }}
$$

$F_{4}$ is the configuration factor for diffuse light emitted from the sky that is reflected at a panel and received by an opposing panel. $\dot{Q}_{\text {bio,DHI,R-refl_1 }}$ is the fraction of radiative energy that is converted into algae biomass (calculation not shown; please refer to Section S.1.2.1 for the calculation principle).

In case of reflections in the culture medium, light does not keep its direction as in case of the reactor wall, but is reflected in all directions of space. Therefore, two configuration factors are needed to describe the radiative heat transfer. The first configuration factor, $F_{1}$, represents light being emitted from the sky and hitting the first panel, while the second configuration factor, $F_{2}$, describes radiative heat transfer between the two panels.

$$
\dot{Q}_{\text {DHI,R-refl_2 }}=2\left(1-\alpha_{\text {alb,R }}\right) \tau_{\text {dif,in }} F_{2} \cdot \tau_{\text {dif,out }} \alpha_{\text {alb,R }} \tau_{\text {dif,in }} F_{1} \cdot d l I_{0, \text { DHI }}
$$


Analogous to direct sunlight $\left(\dot{Q}_{\text {DNI,R-refl_2, }}\right.$ see Section S1.2.6.1), diffuse sunlight is assumed to lack of wavelengths in the photosynthetically active spectrum, when reflected by the culture medium. Therefore, the corresponding term for biomass generation is missing in Equation S20.

\section{S1.2.6.3 Longwave downwelling IR radiation reflected by a panel and received by the} opposing panel, $\dot{Q}_{\mathrm{atm}, \mathrm{IR}, \mathrm{R}-\mathrm{refl}}$

The atmospheric thermal radiation reflected by a panel and received by the opposing panel can be expressed by:

$$
\dot{Q}_{\text {atm, IR,R-refl }}=2 \varepsilon_{\mathrm{R}}\left(1-\varepsilon_{\mathrm{R}}\right) F_{4} \cdot l d I_{\text {sky,IR }}
$$

In contrast to radiation in the visible spectrum, for infrared radiation the emissivity rather than the albedo is used as a measure to describe reflection and absorption at the panels. As infrared radiation cannot be utilized by the algae for biomass accumulation, the respective term is not included in the equation above.

\section{S1.2.6.4 Reactor heat radiaton reflected by an opposing panel and received by the} original reactor, $\dot{Q}_{\text {reactor,IR,R-refl }}$

Heat radiation reflected by an opposing panel and sent back to the original reactor is calculated according to Equation S22.

$$
\dot{Q}_{\text {reactor, IR,R-refl }}=2 \varepsilon_{\mathrm{R}}\left(1-\varepsilon_{\mathrm{R}}\right) F_{5} \cdot \varepsilon_{\mathrm{R}} h l \sigma T_{\mathrm{R}}^{4}
$$

The configuration factor $F_{5}$ describes the reflection of light at parallel plates. 


\section{S1.2.6.5 Ground heat radiation reflected by a panel and received by the opposing panel,} $\dot{Q}_{\text {ground,IR,R-refl }}$

Thermal radiation originating from the ground is reflected by the reactor panels to the opposing panel wall. The corresponding heat flux is determined with the following equation:

$$
\dot{Q}_{\text {ground, IR,R-refl }}=2 \varepsilon_{\mathrm{R}}\left(1-\varepsilon_{\mathrm{R}}\right) F_{5} \cdot \varepsilon_{\mathrm{G}} \sigma l d T_{\mathrm{G}}^{4}
$$

\section{S1.2.7 Reflection of direct, diffuse and thermal radiation at the ground, $\dot{Q}_{\text {ground,refl }}$}

Incoming irradiation is reflected by the ground to the neighboring panels. The following heat fluxes are considered in the temperature model and summarized to $\dot{Q}_{\text {ground,refl. }}$

$$
\dot{Q}_{\text {ground,refl }}=\dot{Q}_{\text {DNI, G-refl }}+\dot{Q}_{\text {DHI, G-refl }}+\dot{Q}_{\text {atm,IR, G-refl }}+\dot{Q}_{\text {reactor,IR, G-refl }}
$$

A detailed description of the single heat fluxes contributing to $\dot{Q}_{\text {ground,refl }}$ is given in the next sections.

\section{S1.2.7.1 Direct sunlight reflected by the ground and received by a reactor panel,} $\dot{Q}_{\text {DNI,G-refl }}$

Direct sunlight falls on the ground when the projected panel height, $h$, is larger than the actual panel height, $h$. Equations for the calculation of $h^{\prime}$ can be found in Section S1.2.1. In contrast to the reactor surface, the ground is not a smooth plane and therefore light is scattered and reflected in all directions of space. Figure S6 displays the geometry of the incoming direct sunlight and the subsequent reflection. As can be seen from the figure, the distance to the irradiated ground area differs with respect to the considered panel side. As both, the back and 
the front of the reactor, receive reflected sunlight, two different configuration factors, $F_{6}$ and $F_{7}$, are used for calculating the respective heat flux $\dot{Q}_{\text {DNI,G-refl }}$ (see Equation 25).

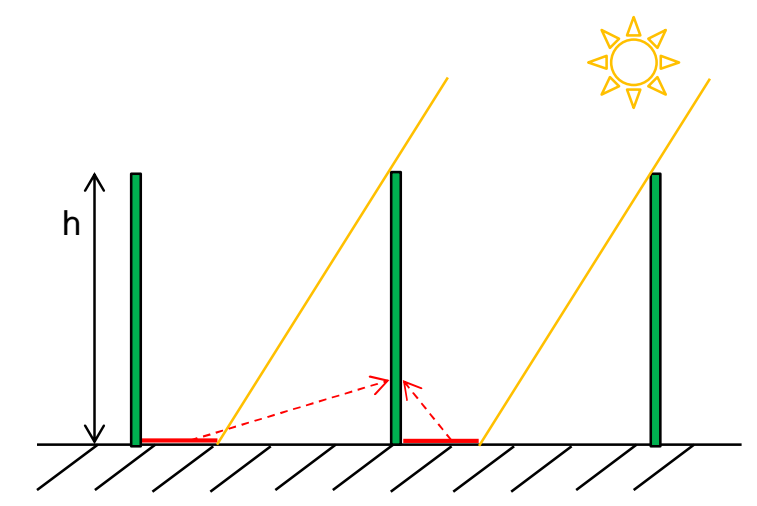

Figure S6. Reflections of direct sunlight from the ground to the front and the back of the reactor panels

$$
\dot{Q}_{\mathrm{DNI}, \mathrm{G}-\mathrm{refl}}=\left(1-\alpha_{\mathrm{alb}, \mathrm{R}}\right) \tau\left(F_{6}+F_{7}\right) \alpha_{\mathrm{alb}, \mathrm{G}} A_{\mathrm{G}}^{\prime} \sin (\alpha) I_{0, \mathrm{DNI}}-\dot{Q}_{\mathrm{bio}, \mathrm{DNI}, \mathrm{G}-\mathrm{refl}}
$$

As sunlight is partly converted into biomass, the respective biomass fixation, $\dot{Q}_{\text {bio,DNI,G-refl, }}$ is substracted from $\dot{Q}_{\mathrm{DNI}, \mathrm{G}-\mathrm{refl}}$. Calculation details for $\dot{Q}_{\text {bio,DNI,G-refl }}$ are not shown here, however, the basic principle for the calculation of the biomass fixation is described in Section S1.2.1. The section of the ground that is illuminated by direct sunlight, $A_{\mathrm{G}}$ ', is defined as

$$
A_{\mathrm{G}}^{\prime}=d^{\prime} \cdot l
$$

where $d^{\prime}$ is the width of the illuminated ground area. Using the theorem of intercepting lines (Figure $\mathrm{S} 7) A_{\mathrm{G}}$ ' can also be expressed as: 


$$
A_{\mathrm{G}}^{\prime}=\frac{h^{\prime}-h}{h} d l
$$

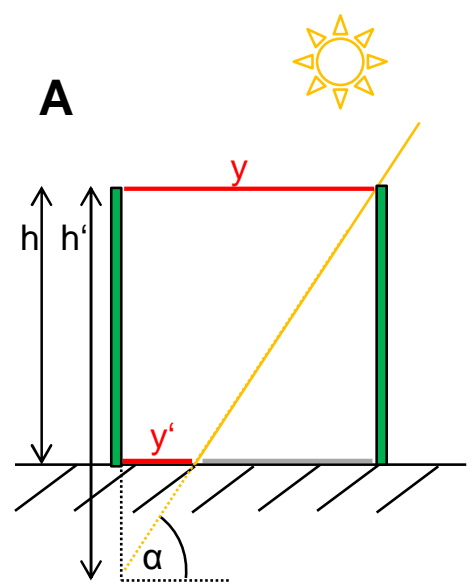

B

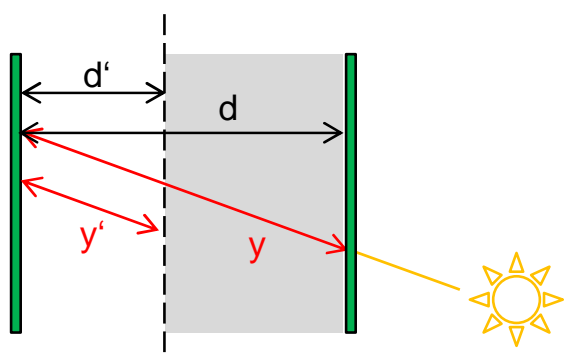

Theoreme of intercepting lines: $\frac{h^{\prime}-h}{h^{\prime}}=\frac{y^{\prime}}{y}=\frac{d \prime}{d}$

Figure S7. Illustration of shaded and irradiated ground areas between two panels for direct solar irradiation: (A) view from the side, (B) view from the top.

\section{S1.2.7.2 Diffuse sunlight reflected by the ground and received by the reactor panels, $\dot{Q}_{\text {DHI,G-refl }}$}

Two configuration factors are required to describe sunlight reflected by the ground and received by the reactor panels. The first configuration factor, $F_{8}$, represents the ratio of light received by the ground to diffuse sunlight entering the algae plant from the opening between the panel rows. The second configuration factor, $F_{1}$, describes the radiative heat transfer between the panel and the ground. Both configuration factors are included in the calculation of $\dot{Q}_{\mathrm{DHI}, \mathrm{G}-\mathrm{refl}}$ :

$$
\dot{Q}_{\mathrm{DHI}, \mathrm{G}-\mathrm{refl}}=2\left(1-\alpha_{\mathrm{alb}, \mathrm{R}}\right) \tau_{\mathrm{Diff,in}} F_{1} \cdot \alpha_{\mathrm{alb}, \mathrm{G}} F_{8} \cdot l d I_{0, \mathrm{DHI}}-\dot{Q}_{\mathrm{bio}, \mathrm{DHI}, \mathrm{G}-\mathrm{refl}}
$$


The fraction of reflected sunlight, which is converted into algae biomass is $\dot{Q}_{\text {bio,DHI,G-refl. For }}$ more information about how biomass fixation is calculated within the model please refer to Section S1.2.1

\section{S1.2.7.3 Longwave downwelling IR radiation reflected by the ground and received by} the reactor panels, $\dot{Q}_{\text {atm,IR,G-refl }}$

Similar to diffuse atmospheric radiation, IR-radiation enters the algae plant through the opening between the panel rows. The thermal radiation is received by the ground and partly scattered back in all directions of space. A fraction of the reflected radiation is absorbed by the reactor panels. This fraction, $\dot{Q}_{\mathrm{atm}, \mathrm{IR}, \mathrm{G}-\mathrm{refl}}$, is calculated according to the following equation:

$$
\dot{Q}_{\text {atm, IR,G-refl }}=2 \varepsilon_{\mathrm{R}} F_{1} \cdot\left(1-\varepsilon_{\mathrm{R}}\right) F_{8} \cdot l d I_{\text {sky,IR }}
$$

Again, the configuration factors $F_{8}$ and $F_{1}$ are used to calculate the two step radiative heat transfer.

\section{S1.2.7.4 Reactor heat radiation reflected by the ground and received by the panels,}

$\dot{Q}_{\text {reactor,IR,G-refl }}$

Photobioreactors emit thermal radiation that is received by the ground. The fraction of radiation that is reflected back from the ground to panels is described by:

$$
\dot{Q}_{\mathrm{atm}, \mathrm{IR}, \mathrm{G}-\mathrm{refl}}=4 \varepsilon_{\mathrm{R}} F_{1} \cdot\left(1-\varepsilon_{\mathrm{R}}\right) F_{9} \cdot \varepsilon_{\mathrm{R}} h l \sigma T_{\mathrm{R}}^{4}
$$


$F_{9}$ and $F_{1}$ are the configuration factors describing radiative heat transfer from a panel to the ground and from the ground back to the panel, respectively. The factor 4 at the beginning of the term results from the fact that two reactor surfaces emit thermal radiation to the ground and further that two ground surfaces reflect and scatter the light to the front and back of the respective panel.

\section{S1.2.8 Heat transfer through natural air convection, $\dot{Q}_{\text {convection }}$}

Convection is a non-radiative heat transfer that affects reactor temperature. Two forms of convection must be distinguished. Forced convection occurs when an external current, such as wind, is responsible for the motion of the fluid. In contrast, natural convection occurs even without the presence of an external current. For example, when air is heating up at a warm plate it starts to move upwards. Natural convection therefore generates its own motion resulting from gradients in specific weight, which originate from temperature differences between the bulk medium and the fluid in the boundary layer.

For the proposed model, only natural convection is considered. As mentioned in the main publication, wind is typically measured $10 \mathrm{~m}$ above ground. Thus the wind speed in the TMY3 dataset can only poorly be translated into air movement at plant level. Another crucial point is that the panel lines act as a windbreaker, therefore reducing the wind speed for the panel line behind it, but on the other hand creating turbulences. In summary, the determination of the air velocity and its direction with respect to the panel surfaces is a rather complex problem, requiring detailed computational fluid dynamic studies. As this is out of the scope of the present study, only natural convection is considered.

Convection has a moderating effect on the reactor temperature, typically reducing the maximum temperatures reached in the reactor. As forced convection typically enforces the heat exchange, the assumed natural convection can also be seen as a conservative approximation. 
The heat exchange is defined as:

$$
\dot{Q}_{\text {convection }}=2 h l \cdot \alpha_{\text {heat }}\left(T_{\text {air }}-T_{\mathrm{R}}\right)
$$

The heat transfer coefficient, $\alpha_{\text {heat }}$, can be calculated from the dimensionless Nusselt number, $N u$, the thermal conductivity of air, $\lambda_{\text {air, }}$ and the characteristic length, $L$ (in case of vertical flat panel photobioreactors $L=h$ ).

$$
\alpha_{\text {heat }}=\frac{N u \cdot \lambda_{\text {air }}}{L}
$$

According to Kabelac et al. ${ }^{5}$, the Nusselt number for natural convection at a vertical flat plate is given by

$$
N u=\left[0.825+0.387(R a \cdot f(P r))^{1 / 6}\right]^{2}
$$

where $R a$ is the Rayleigh number and $f(P r)$ is a function describing the influence of the Prandtl number, $P r$, on the Nusselt number:

$$
f(\operatorname{Pr})=\left[1+\left(\frac{0.492}{P r}\right)^{9 / 16}\right]^{-16 / 9}
$$

\section{S1.2.9 Heat transfer related to the aeration of the reactor panels, $\dot{Q}_{\text {aeration }}$}

In vertical flat panel photobioreactors, aeration is required to provide agitation of the culture medium. The air is typically added at the bottom of the reactor and the rising gas bubbles 
generate the desired level of turbulence. Carbon dioxide needed for algae biomass build-up can either be premixed with the instreaming air or enters the reactor through a separate gas line. The amount of instreaming air can be expressed by the aeration rate $\left(v^{\prime}\right)$, the volume of air per culture volume and time. ${ }^{18}$ Typical aeration rates mentioned in the literature for outdoor algae cultivation lie between 0.05 and $0.3 \mathrm{~min}^{-1} \cdot{ }^{18,19}$ In the model, an intermediate value of $0.1 \mathrm{~min}^{-1}$ is chosen.

The heat flux related to the aeration of the photobioreactors, $\dot{Q}_{\text {aeration, }}$ as considered in the model, is caused by three major effects. First, the gas bubbles rising through the water column are getting saturated with water from the reactor. The evaporation of water results in cooling of the medium. Second, due to temperature differences, heat is directly exchanged between the instreaming gas and the surrounding water. Third, the air has to be compressed in order overcome the hydrostatic pressure of the water column. The mechanical work that is applied for the compression is released in the culture medium as the gas bubbles expand during their way up to the water surface.

The total heat flux related to the aeration of the reactors can be calculated from the enthalpy difference between the ingoing and outgoing gas stream, $\dot{H}_{\text {in,gas }}$ and $\dot{H}_{\text {out,gas }}$, the enthalpy of the make-up water replacing the evaporation losses, $\dot{H}_{\text {make-up water, and the power for gas }}$ compression, $P_{\text {mech,aeration }}$.

$$
\dot{Q}_{\text {aeration }}=\dot{H}_{\text {in,gas }}-\dot{H}_{\text {out,gas }}+\dot{H}_{\text {make-up water }}+P_{\text {mech,aeration }}
$$

The following assumptions are made for the calculation of $\dot{Q}_{\text {aeration: }}$ :

- the thermal properties of the instreaming gas are the properties of air

- the mass flow of instreaming and outgoing gas stays constant 
- the relative humidity and the temperature of instreaming gas equals the humidity and temperature of the surrounding air

- the relative humidity of outgoing air is $100 \%$ (completely saturated) and the gas temperature at the outlet equals the reactor temperature

- the temperature of the make-up water equals the reactor temperature

- the reference point for the enthalpy is $0{ }^{\circ} \mathrm{C}$.

With these assumptions the enthalpies $\dot{H}_{\text {in,gas }}, \dot{H}_{\text {out,gas }}$ and $\dot{H}_{\text {make-up water }}$ can be written as

$$
\begin{gathered}
\dot{H}_{\text {in,gas }}=\dot{m}_{\text {air }}\left[c_{\mathrm{P}, \text { air }} T_{\text {in }}+x\left(r_{0}+c_{\mathrm{P}, \text { vapor }} T_{\text {air }}\right)\right], \\
\dot{H}_{\text {out,gas }}=\dot{m}_{\text {air }}\left[c_{\mathrm{P}, \text { air }} T_{\mathrm{R}}+x_{\mathrm{s}}\left(r_{0}+c_{\mathrm{P}, \text { vapor }} T_{\mathrm{R}}\right)\right], \\
\dot{H}_{\text {make-up water }}=\dot{m}_{\text {air }}\left(x-x_{s}\right) c_{\mathrm{P}, \mathrm{W}} T_{\mathrm{R}},
\end{gathered}
$$

where $\dot{m}_{\text {air }}$ is the mass flow of the gas used for aeration, $c_{\mathrm{P} \text {,air }}$ and $c_{\mathrm{P} \text {,vapor }}$ are the heat capacities of the air and water vapor and $r_{0}$ is the evaporation enthalpy of water at $0{ }^{\circ} \mathrm{C}$. $x$ is the water content of the air and $x_{\mathrm{s}}$ is the water content of the air at the point of saturation.

The mechanical power input required for aeration is calculated according to Chisti. ${ }^{20}$ The respective equation for the energy input is derived from the energy related to the expansion of gas bubbles rising through the reactor column. The terms used to calculate this energy input are independent of the shape of the cross-sectional area and can therefore be applied to flat panel photobioreactors: 


$$
P_{\text {mech,aeration }}=Q_{\mathrm{m}} R T_{\text {air }} \ln \left(1+\frac{\rho_{\mathrm{R}} g h_{\mathrm{L}}}{P_{\mathrm{h}}}\right)
$$

$\dot{Q}_{\mathrm{m}}$ is the molar gas flow rate, $R$ the gas constant, $g$ the gravity on earth, $P_{\mathrm{h}}$ the pressure in the head zone and $h_{\mathrm{L}}$ the height of the liquid column above the point of gas injection. For the model, we assume that gas injection occurs at the bottom of the reactor and further that the reactors are completely filled with algae medium. Therefore, the height of the liquid column $h_{\mathrm{L}}$ is identical with the reactor height $h$.

Apart from the compression energy that is released by the expansion of the gas bubbles, kinetic energy has to be applied at the sparger of reactor. However, Chisti ${ }^{20}$ states that the fraction of energy related to the sparger is rather small compared to the overall mechanical energy required for aeration. Therefore, kinetic energy input is neglected in the temperature simulation. 


\section{S2 Supplementary temperature simulations and related}

\section{content}

\section{S2.1 Influence of the reactor height on the temperature profile assuming a constant ratio between height and panel distance}

Three reactor configurations are compared in order to determine the influence of the reactor height on the temperature profile. The ratio between the height and panel distance is kept constant for the three configurations (Figure S8).

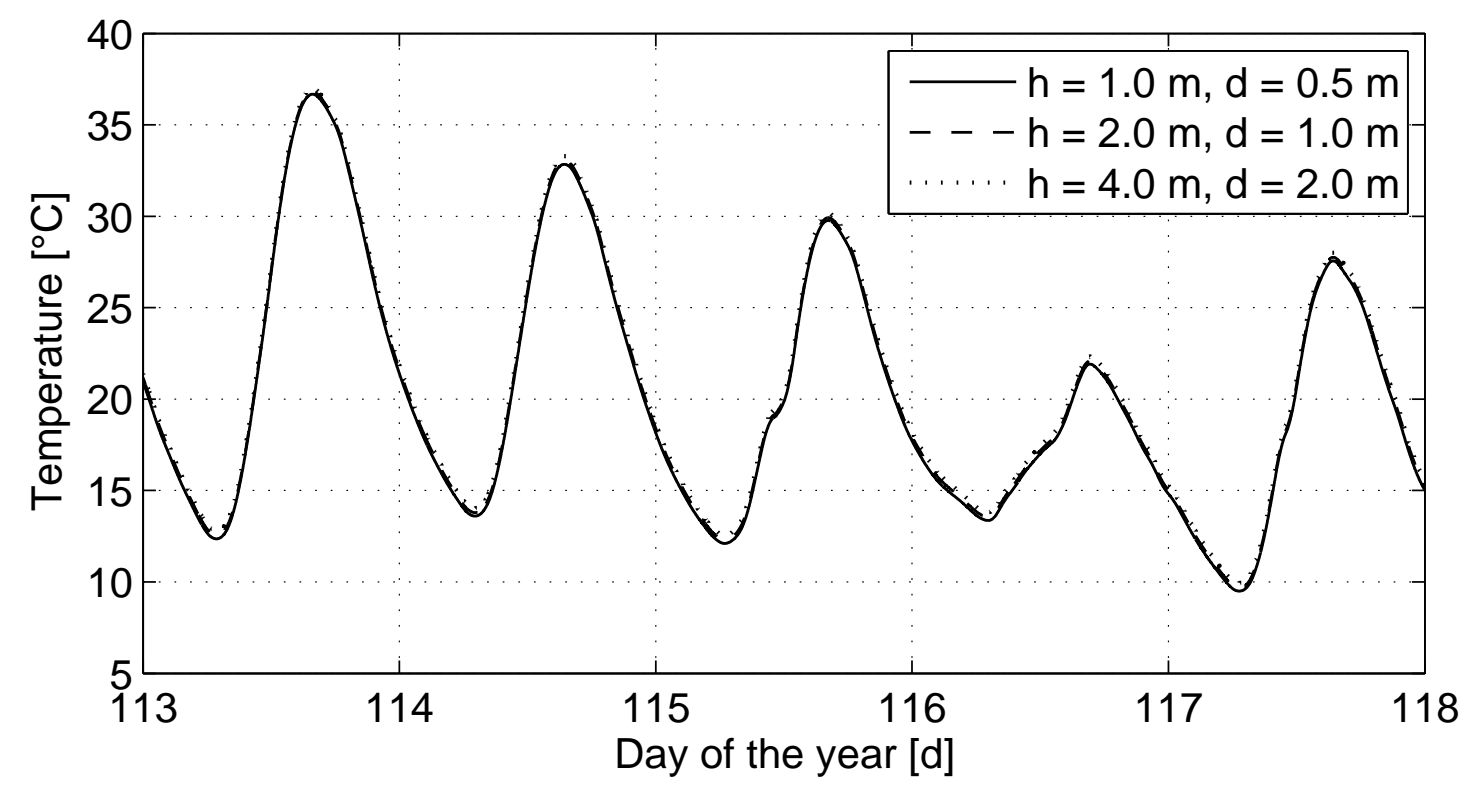

Figure S8. Temperature profiles for different reactor heights and panel distances (solid line, $1 \mathrm{~m} / 0.5 \mathrm{~m}$, dashed line, $2 \mathrm{~m} / 1 \mathrm{~m}$; dotted line, $4 \mathrm{~m} / 2 \mathrm{~m}$ ). The ratio between reactor height and panel distance is kept constant at a value of 2 . The simulations are performed for Sacramento, CA, assuming a north-south orientation of the panels.

The simulation demonstrates that basically no difference exists between the single temperature profiles. Consequently, the results of a certain reactor configuration can be 
transferred with good approximation to another configuration, provided that the ratio between height and panel distance is kept constant. Small deviations between the individual profiles at peak temperatures mostly originate from the influence of the convection term. In contrast to radiation-related heat fluxes, convection does not scale directly with height-distance-ratio. The reason for this is the influence of the characteristic length, $L$, on the calculation of the convection-based heat transfer. (see Equation S32; furthermore $L$ is also required for the calculation of the Raleigh-Number, $R a$; equation not displayed in this document).

\section{S2.2 Impact of the biomass fixation rate and the albedo of the culture medium on the outcome of the temperature simulation}

A sensitivity analysis is performed in order examine the impact of the biomass fixation rate on various results of the temperature simulation. The selected reactor for the analysis is situated in Sacramento, CA, and has a panel distance of $0.5 \mathrm{~m}$ and a panel thickness of $0.05 \mathrm{~m}$ (Table S2).

According to the results of the study, the biomass fixation rate only has a small impact on maximum and average reactor temperatures $\left(\Delta T_{R}<0.65{ }^{\circ} \mathrm{C}\right)$. The number of days when the reactor temperature drops below $0{ }^{\circ} \mathrm{C}$ is not affected by the variation of the biomass fixation rate. In contrast, the number of days when the reactor temperature exceeds $40{ }^{\circ} \mathrm{C}$ decreases with an increase of the fixation rate. This moderate dependency can be explained by the fact that in the considered case the reactor temperature often exceeds $40{ }^{\circ} \mathrm{C}$ only by few tenths of a degree. Thus, even a small decrease in peak temperatures may lead to a reduction of the number of days when the $40{ }^{\circ} \mathrm{C}$-threshold is crossed. With respect to the heating and cooling demand of the reactors, a moderate dependency on the biomass fixation rate is visible. In this context, it is important to keep in mind that the absolute energy demand for the chosen reactor is small compared to other locations or more strict temperature limitations (Fig. 5 of the 
manuscript). In cases where the absolute energy requirements are much higher, the relative impact of the biomass fixation rate would be significantly reduced.

Table S2. Influence of the biomass fixation rate on important results of the temperature simulation (location, Sacramento, CA; panel distance, $0.5 \mathrm{~m}$; panel thickness $0.05 \mathrm{~m}$; orientation, north-south)

\begin{tabular}{llllllll}
\hline $\begin{array}{l}\text { Biomass fix- } \\
\text { ation rate, } X_{\text {Bio }} \\
{[-]}\end{array}$ & $\begin{array}{lllll}T_{\min }{ }^{a} \\
{\left[{ }^{\circ} \mathrm{C}\right]}\end{array}$ & $\begin{array}{l}T_{\text {average }} \\
{\left[{ }^{\circ} \mathrm{C}\right]}\end{array}$ & $\begin{array}{l}T_{\max } \\
{\left[{ }^{\circ} \mathrm{C}\right]}\end{array}$ & $\begin{array}{l}\text { Nr. of days } \\
T_{\mathrm{R}}<0^{\circ} \mathrm{C} \\
{[-]}\end{array}$ & $\begin{array}{l}\text { Nr. of days } \\
T_{\mathrm{R}}>40^{\circ} \mathrm{C} \\
{[-]}\end{array}$ & $\begin{array}{l}\text { Heating } \\
\text { demand }^{\mathrm{b}} \\
{\left[\mathrm{MJ} \mathrm{m}^{-2} \mathrm{a}^{-1}\right]}\end{array}$ & $\begin{array}{l}\text { Cooling } \\
\text { demand }^{\mathrm{c}} \\
{\left[\mathrm{MJ} \mathrm{m}^{-2} \mathrm{a}^{-1}\right]}\end{array}$ \\
\hline 0.005 & $<0$ & 19.212 & 45.572 & 3 & 40 & 2.4017 & -34.534 \\
0.010 & $<0$ & 19.177 & 45.466 & 3 & 38 & 2.4149 & -32.781 \\
0.015 & $<0$ & 19.142 & 45.360 & 3 & 36 & 2.4281 & -31.116 \\
0.020 & $<0$ & 19.107 & 45.254 & 3 & 35 & 2.4415 & -29.516 \\
0.025 & $<0$ & 19.072 & 45.148 & 3 & 34 & 2.4549 & -27.974 \\
0.030 & $<0$ & 19.037 & 45.041 & 3 & 32 & 2.4684 & -26.480 \\
0.035 & $<0$ & 19.002 & 44.934 & 3 & 31 & 2.4818 & -25.066
\end{tabular}

\footnotetext{
${ }^{\mathrm{a}}$ Reactor temperatures below $0{ }^{\circ} \mathrm{C}$ are not implemented in the temperature model as ice formation may damage the reactors

${ }^{\mathrm{b}}$ For the case that the reactor is not allowed to drop below $0{ }^{\circ} \mathrm{C}$

${ }^{\mathrm{c}}$ For the case that the reactor is not allowed to exceed $40{ }^{\circ} \mathrm{C}$
}

Apart from the biomass production rate, a second sensitivity analysis was performed for the albedo of the reactor (Table S3). The standard value used for the albedo throughout this publication is 0.3 . This value is representative for thick plant leaves and was therefore used to approximate the absorption of visible sunlight by the algae cell culture. The actual value of the albedo, however, depends on the respective algae strain, current growth conditions and the cell density with respect to the light path (panel thickness). The latter is very important as long as sunlight can pass through the reactor panel (transmission). However, for dense algae cultures, we expect that basically all light is either absorbed or reflected by the panel. A further increase of biomass concentration will thus not lead to a higher quantity of absorbed solar energy, but only have the effect that sunlight is absorbed closer to the reactor wall. 
Moreover, continuous biomass production at constant cell densities is assumed for the simulations. Therefore, the albedo of the reactor is considered independent of reactor dimensions and biomass concentration in this study.

For the sensitivity analysis, the value of the albedo is varied between 0.1 and 0.5 . Most plants absorb between $60 \%$ and $80 \%$ of solar light, resulting in an albedo of 0.2 to 0.4 (assuming there is no or only minor transmission of light). ${ }^{1}$ Only very dark 'leaves', such as pine needles, absorb close to $90 \%$ of solar energy (albedo of 0.1 ). As the results demonstrate, the albedo of the reactor has a relatively strong influence on the temperature-related parameters, with the exception of the heating demand. Heating is most needed at the coldest time of day, i.e. in night or just before sunrise. As absorption of visible sunlight only happens during daytime, the lower nighttime temperatures are barely affected by the albedo.

Table S3. Influence of the albedo on important results of the temperature simulation (location, Sacramento, CA, panel distance $0.5 \mathrm{~m}$; panel thickness $0.05 \mathrm{~m}$; orientation, northsouth)

\begin{tabular}{llllllll}
\hline $\begin{array}{l}\text { Albedo, } \alpha_{\text {alb,R }} \\
{[-]}\end{array}$ & $\begin{array}{l}T_{\min }{ }^{\mathrm{a}} \\
{\left[{ }^{\circ} \mathrm{C}\right]}\end{array}$ & $\begin{array}{l}T_{\text {average }} \\
{\left[{ }^{\circ} \mathrm{C}\right]}\end{array}$ & $\begin{array}{l}T_{\max } \\
{\left[{ }^{\circ} \mathrm{C}\right]}\end{array}$ & $\begin{array}{l}\text { Nr. of days } \\
T_{\mathrm{R}}<0^{\circ} \mathrm{C} \\
{[-]}\end{array}$ & $\begin{array}{l}\text { Nr. of days } \\
T_{\mathrm{R}}>40^{\circ} \mathrm{C} \\
{[-]}\end{array}$ & $\begin{array}{l}\text { Heating } \\
\text { demand }^{\mathrm{b}} \\
{\left[\mathrm{MJ} \mathrm{m}^{-2} \mathrm{a}^{-1}\right]}\end{array}$ & $\begin{array}{l}\text { Cooling } \\
\text { demand }^{\mathrm{c}} \\
{\left[\mathrm{MJ} \mathrm{m}^{-2} \mathrm{a}^{-1}\right]}\end{array}$ \\
\hline 0.1 & $<0$ & 20.273 & 48.739 & 2 & 92 & 2.0347 & -133.81 \\
0.2 & $<0$ & 19.732 & 47.127 & 3 & 65 & 2.2112 & -71.676 \\
0.3 & $<0$ & 19.142 & 45.360 & 3 & 36 & 2.4281 & -31.116 \\
0.4 & $<0$ & 18.498 & 43.412 & 3 & 16 & 2.6732 & -10.440 \\
0.5 & $<0$ & 17.796 & 41.250 & 3 & 5 & 2.9481 & -1.8016 \\
\hline
\end{tabular}

\footnotetext{
${ }^{a}$ Reactor temperatures below $0{ }^{\circ} \mathrm{C}$ are not implemented in the temperature model as ice formation may damage the reactors

${ }^{\mathrm{b}}$ For the case that the reactor is not allowed to drop below $0{ }^{\circ} \mathrm{C}$

${ }^{\mathrm{c}}$ For the case that the reactor is not allowed to exceed $40{ }^{\circ} \mathrm{C}$
} 


\section{S2.3 Temperature profiles for various locations and geometries}

\section{S2.3.1 Overview of examined locations}

Table S4. Overview of U.S. locations studied within the publication

\begin{tabular}{|c|c|c|c|c|c|c|}
\hline Location & U.S.-state & Longitude & Latitude & Elevation & Climate $^{\mathrm{a}}$ & $\begin{array}{l}\text { Ground water } \\
\text { temperature }\end{array}$ \\
\hline Forks & WA & $47.933^{\circ}$ & $-124.567^{\circ}$ & $55 \mathrm{~m}$ & $\begin{array}{l}\text { Temperate, without } \\
\text { dry season, warm } \\
\text { summer }\end{array}$ & $10^{\circ} \mathrm{C}$ \\
\hline Boston & MA & $42.367^{\circ}$ & $-71.017^{\circ}$ & $6 \mathrm{~m}$ & $\begin{array}{l}\text { Cold, without dry } \\
\text { season, warm/hot } \\
\text { summer }\end{array}$ & $9.5^{\circ} \mathrm{C}$ \\
\hline Sacramento & $\mathrm{CA}$ & $38.500^{\circ}$ & $-121.500^{\circ}$ & $5 \mathrm{~m}$ & $\begin{array}{l}\text { Temperate, dry and } \\
\text { hot summer }\end{array}$ & $16.0^{\circ} \mathrm{C}$ \\
\hline Phoenix & $\mathrm{AZ}$ & $33.450^{\circ}$ & $-111.983^{\circ}$ & $337 \mathrm{~m}$ & Arid, desert, hot & $22.0^{\circ} \mathrm{C}$ \\
\hline New Orleans & LA & $30.000^{\circ}$ & $-90.250^{\circ}$ & $1 \mathrm{~m}$ & $\begin{array}{l}\text { Temperate, without } \\
\text { dry season, hot } \\
\text { summer }\end{array}$ & $21.5^{\circ} \mathrm{C}$ \\
\hline Hilo & HI & $19.717^{\circ}$ & $-155.050^{\circ}$ & $9 \mathrm{~m}$ & Tropical, rainforest & $23.5^{\circ} \mathrm{C}$ \\
\hline
\end{tabular}

${ }^{\text {a According to Köppen-Geiger climate classification }}{ }^{21}$ 


\section{S2.3.2 Temperature profiles for the 'standard case'}

Figure S9 shows temperature profiles at various locations for the following 'standard case': panel distance: $0.5 \mathrm{~m}$, panel thickness: $0.05 \mathrm{~m}$, orientation: north-south
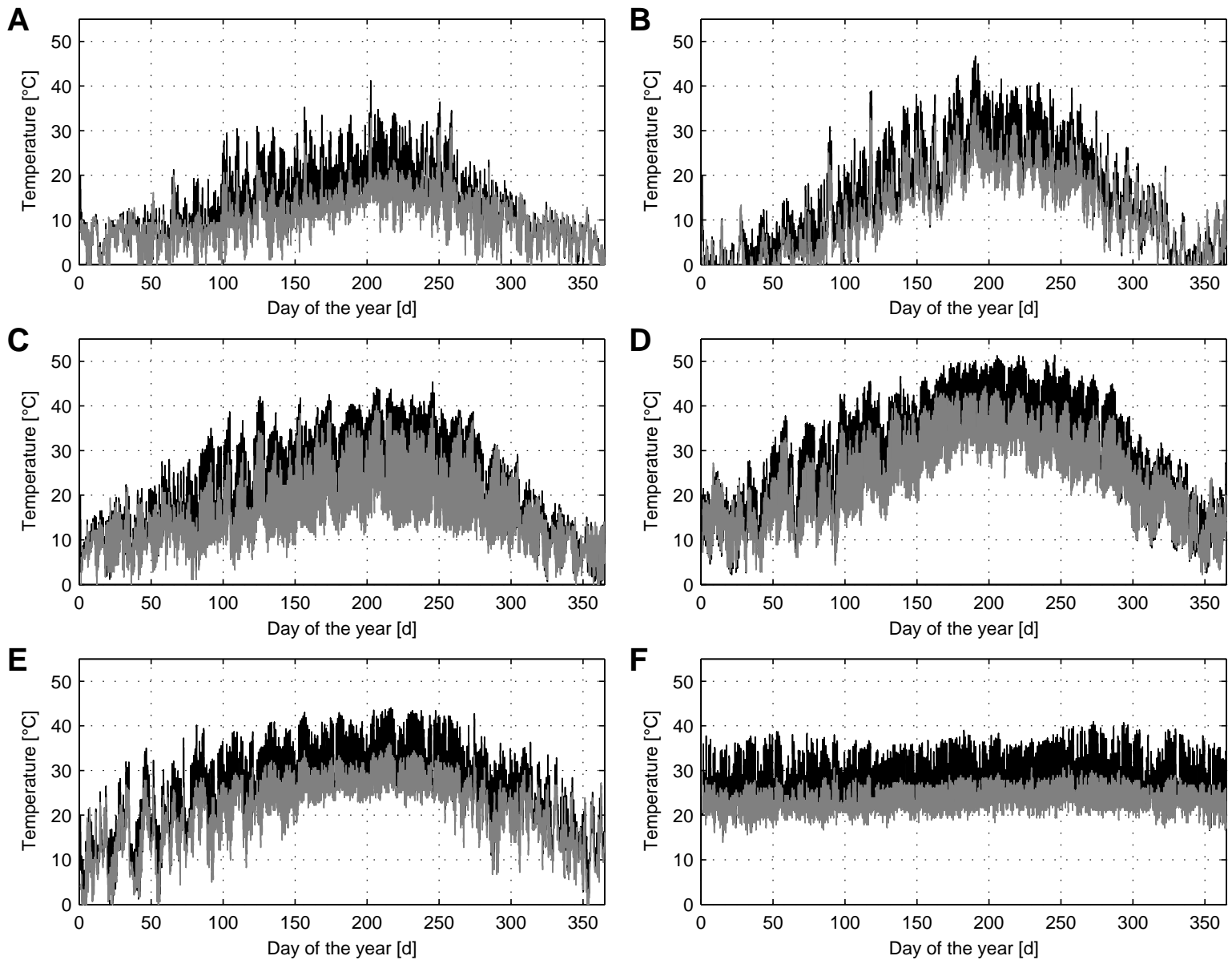

Figure S9. Temperature profiles for reactors with a panel distance of $0.5 \mathrm{~m}$ and a panel thickness of $0.05 \mathrm{~m}$. The panels face in north-south direction. Black and gray lines correspond to the reactor and air temperature, respectively. Simulations are performed for the locations
(A) Forks, WA,
(B) Boston, MA,
(C) Sacramento, CA,
(D) Phoenix, AZ,
(E) New Orleans,

LA, and (F) Hilo, HI. 


\section{S2.3.3 Temperature profiles for reactors facing in east-west direction}

The reactor orientation is changed from north-south to east-west orientation for Figure S10.

Panel distance and thickness are kept constant.
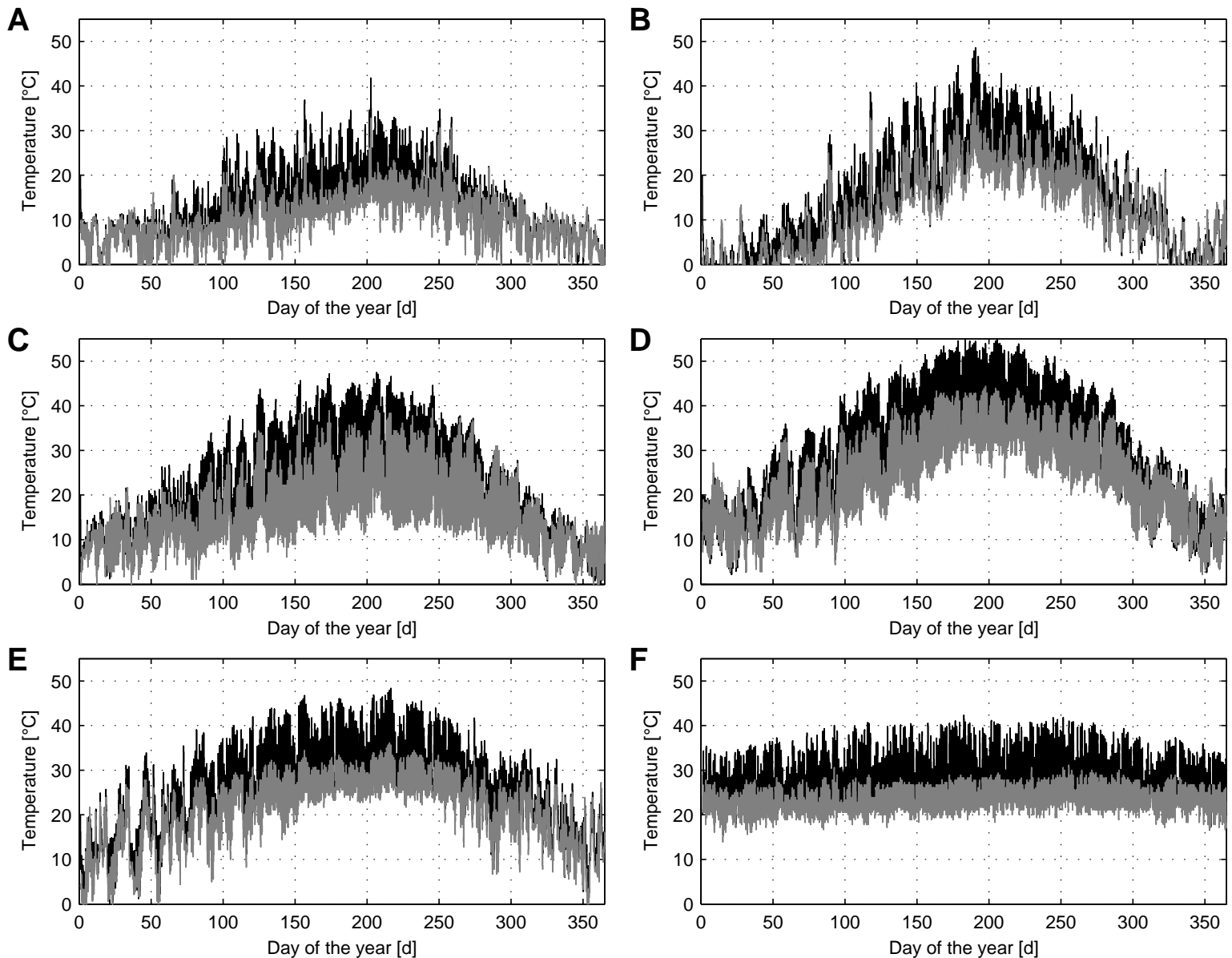

Figure S10. Temperature profiles for reactors with a panel distance of $0.5 \mathrm{~m}$ and a panel thickness of $0.05 \mathrm{~m}$. The panels face in east-west direction. Black and gray lines correspond to the reactor and air temperature, respectively. Simulations are performed for the locations
(A) Forks, WA
(B) Boston, MA,
(C) Sacramento, CA,
(D) Phoenix, AZ,
(E) New Orleans,

LA, and (F) Hilo, HI.. 


\section{S2.3.4 Temperature profiles for an increased panel distance}

For Figure S11, the panel distance is increased to $1.0 \mathrm{~m}$. Panel thickness is kept at $0.05 \mathrm{~m}$ and reactor panels face in north-south direction.
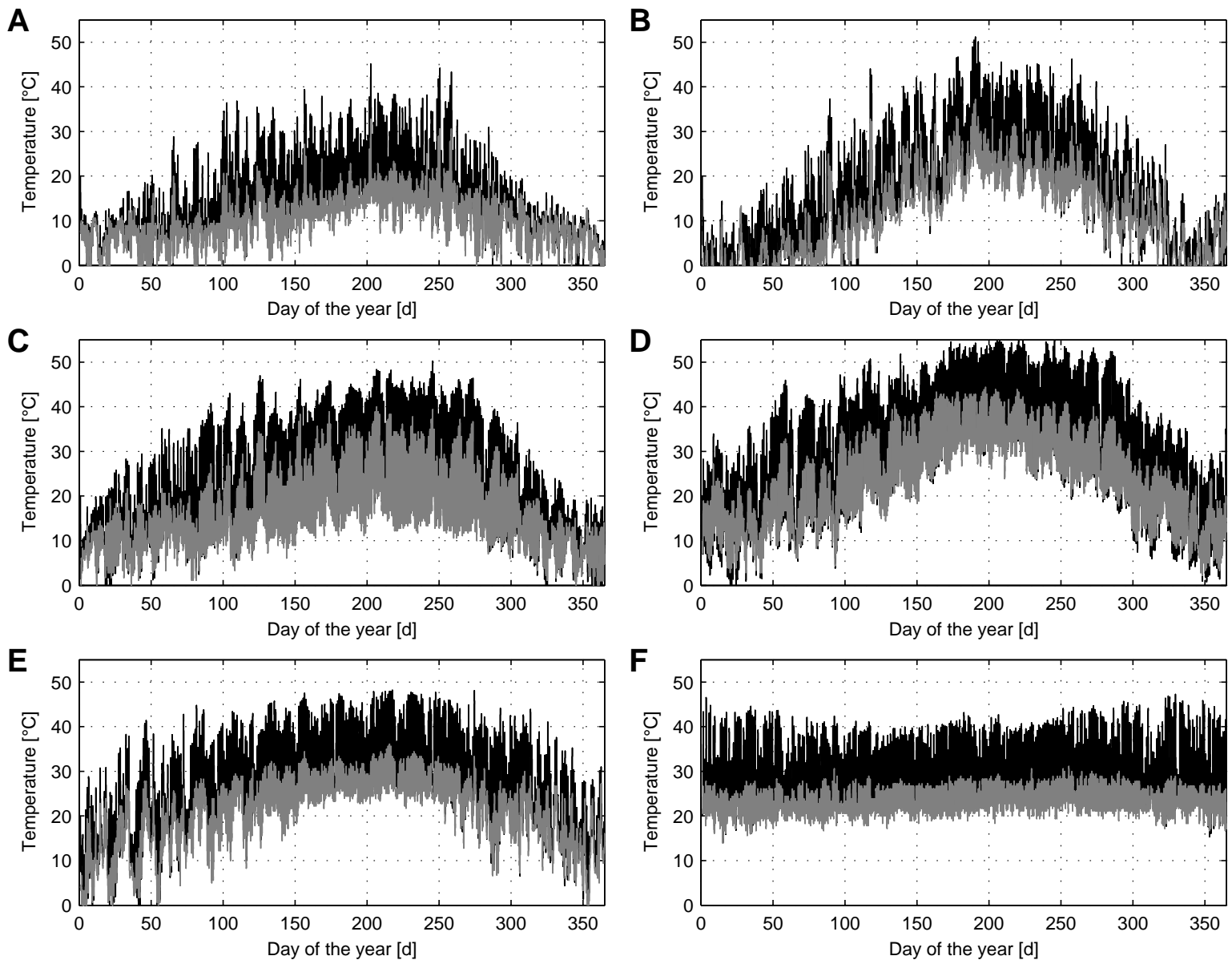

Figure S11. Temperature profiles for reactors with a panel distance of $1.0 \mathrm{~m}$ and a panel thickness of $0.05 \mathrm{~m}$. The panels face in north-south direction. Black and gray lines correspond to the reactor and air temperature, respectively. Simulations are performed for the locations
(A) Forks, WA,
(B) Boston, MA,
(C) Sacramento, CA,
(D) Phoenix, AZ,
(E) New Orleans,

LA, and (F) Hilo, HI.. 


\section{Symbols}

The following figure gives an overview of the configuration factors used in the study. Heat radiation is emitted by the sky, the ground or the panels and received either by the panels or the ground. In the figure, the receiving and emitting areas are marked in red. The arrow indicates the direction of the heat transfer. In case of $\mathrm{F}_{4}$ and $\mathrm{F}_{5}$, additionally reflections at the reactor wall are considered.

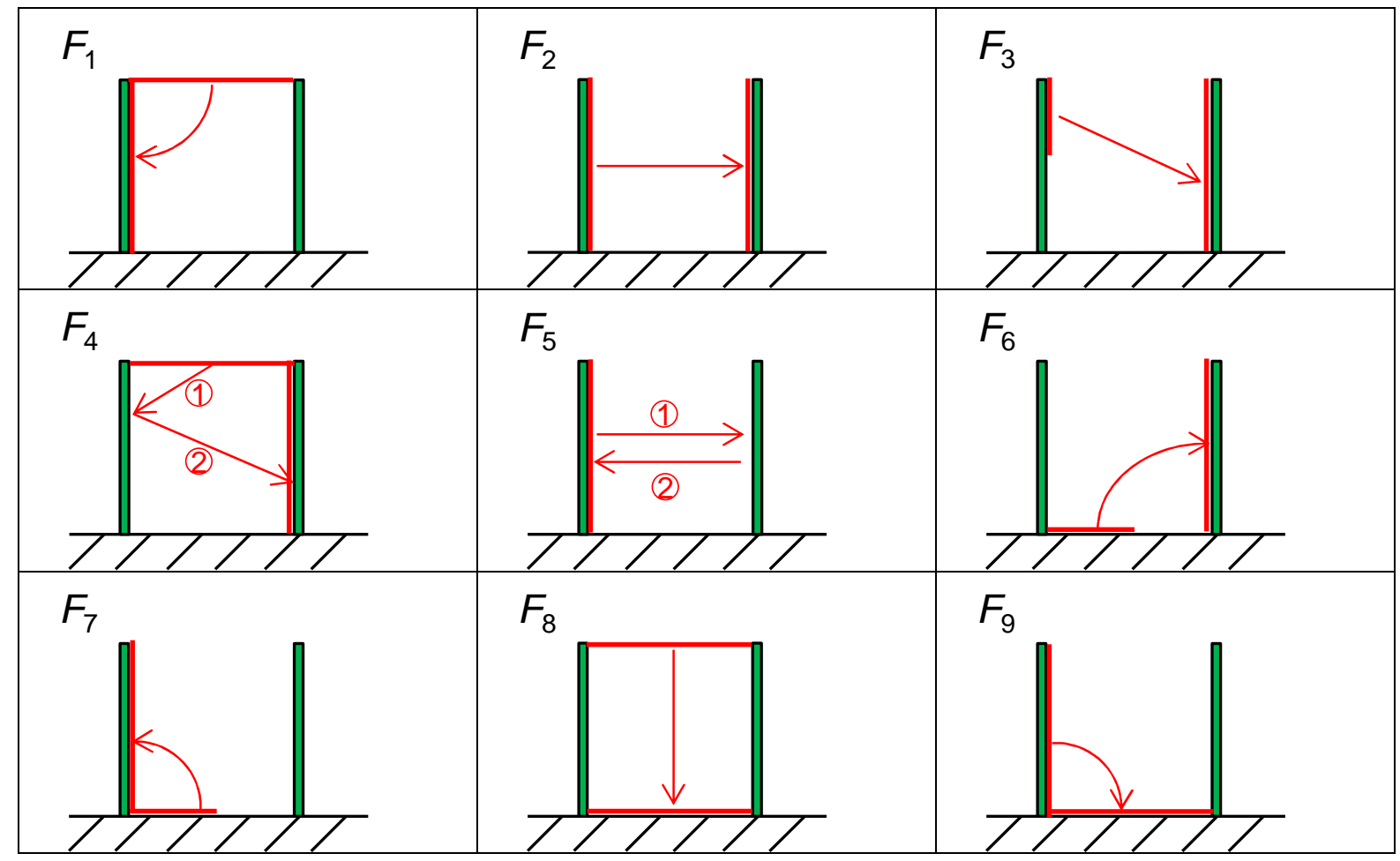

Figure S12. Overview of configuration factors used in this study. Surfaces taking part at the radiative heat transfer are displayed in red. 
Table S5. List of parameters and functions (latin characters)

\begin{tabular}{|c|c|c|c|c|}
\hline Symbol & Definition & Value & Unit & Ref. \\
\hline$A$ & Solar azimuth angle & & $\operatorname{deg}\left(^{\circ}\right)$ & a \\
\hline$A_{\mathrm{R}}$ & Reactor surface area (one side of the panel) & & $\mathrm{m}^{2}$ & a \\
\hline$A_{\mathrm{R}}$ & Illuminated part of the reactor surface area & & $\mathrm{m}^{2}$ & a \\
\hline$c$ & Cloud coverage & dataset & - & 12 \\
\hline$c_{\mathrm{P}, \text { air }}$ & Heat capacity of the air & & $\mathrm{J} \mathrm{kg}^{-3} \mathrm{~K}^{-1}$ & a \\
\hline$c_{\mathrm{P} \text {,vapor }}$ & Heat capacity of water vapor & 1860 & $\mathrm{~J} \mathrm{~kg}^{-3} \mathrm{~K}^{-1}$ & 5 \\
\hline$c_{\mathrm{P}, \mathrm{R}}$ & Heat capacity of the culture medium & 4181 & $\mathrm{~J} \mathrm{~kg}^{-3} \mathrm{~K}^{-1}$ & 22 \\
\hline$c_{\mathrm{P}, \mathrm{V}}$ & Volumetric heat capacity of the ground & $1.5 \cdot 10^{6}$ & $\mathrm{~J} \mathrm{~m}^{-3} \mathrm{~K}^{-1}$ & 11 \\
\hline$d$ & Panel distance & $0.1 \ldots 5$ & $\mathrm{~m}$ & $\mathrm{~b}$ \\
\hline$e_{\mathrm{w}}$ & Water vapor pressure of air & & mbar & a \\
\hline$F_{i}$ & Configuration factor, see Figure S12 for more information & & - & a \\
\hline$g$ & Gravity on earth & 9.81 & $\mathrm{~m} \mathrm{~s}^{-2}$ & 23 \\
\hline$h$ & Height of the reactor & 1 & $\mathrm{~m}$ & $\mathrm{~b}$ \\
\hline$h^{\prime}$ & Projected panel height & & $\mathrm{m}$ & a \\
\hline$h_{\mathrm{L}}$ & $\begin{array}{l}\text { Height of the liquid column in the reactor (here identical to } \\
h)\end{array}$ & & $\mathrm{m}$ & a \\
\hline$\dot{H}_{\text {in,gas }}$ & Enthalpy flow of the instreaming gas used for aeration & & $\mathrm{W}$ & a \\
\hline$\dot{H}_{\text {make-up water }}$ & Enthalpy flow related to the make-up water & & $\mathrm{W}$ & a \\
\hline$\dot{H}_{\text {out,gas }}$ & Enthalpy flow of the outstreaming gas & & $\mathrm{W}$ & a \\
\hline$h_{\mathrm{L}}$ & Height of the water column above the point of gas injection & & $\mathrm{m}$ & a \\
\hline$I_{0, \mathrm{DHI}}$ & Diffuse horizontal irradiance & dataset & $\mathrm{W} \mathrm{m}^{-2}$ & 12 \\
\hline$I_{0, \mathrm{DNI}}$ & Direct normal irradiance & dataset & $\mathrm{W} \mathrm{m}^{-2}$ & 12 \\
\hline$I_{\mathrm{R}, \mathrm{DNI}}$ & $\begin{array}{l}\text { Intensity of incoming direct sunlight related to a vertical } \\
\text { plane }\end{array}$ & & $\mathrm{W} \mathrm{m}^{-2}$ & a \\
\hline$I_{\text {sky,IR }}$ & Atmospheric horizontal IR-irradiance & & $\mathrm{W} \mathrm{m} \mathrm{m}^{-2}$ & a \\
\hline$k_{\mathrm{G}}$ & Heat conductivity of the ground & 0.5 & $\mathrm{~W} \mathrm{~m}^{-1} \mathrm{~K}^{-1}$ & 11 \\
\hline$l$ & Length of a single reactor panel & 2 & $\mathrm{~m}$ & a \\
\hline$L$ & Characteristic length (here identical to $h$ ) & & $\mathrm{m}$ & a \\
\hline $\mathrm{Nu}$ & Nusselt number & & - & a \\
\hline$\dot{m}_{\text {air }}$ & Mass flow of the gas used for aeration & & $\mathrm{kg} \mathrm{s}^{-1}$ & a \\
\hline$P_{\mathrm{h}}$ & Pressure in the head zone (identical to air pressure) & dataset & $\mathrm{Pa}$ & 12 \\
\hline$P_{\text {mech,aeration }}$ & Mechanical power input required for aeration & & $\mathrm{W}$ & a \\
\hline $\operatorname{Pr}$ & Prandtl number & & - & \\
\hline$\dot{Q}_{\text {aeration }}$ & Heat transfer related to the aeration of the reactor panels & & $\mathrm{W}$ & a \\
\hline$\dot{Q}_{\mathrm{atm}, \mathrm{IR}}$ & Atmospheric long-wave irradiation & & $\mathrm{W}$ & a \\
\hline$\dot{Q}_{\text {atm,IR,G-refl }}$ & Atmospheric long-wave irradiation reflected by the ground & & $\mathrm{W}$ & a \\
\hline$\dot{Q}_{\text {atm,IR,R-refl }}$ & Atmospheric long-wave irradiation reflected by the panels & & $\mathrm{W}$ & a \\
\hline$\dot{Q}_{\text {bio,DHI }}$ & Biomass fixation related to diffuse sunlight & & $\mathrm{W}$ & a \\
\hline$\dot{Q}_{\text {bio,DHI,G-refl }}$ & $\begin{array}{l}\text { Biomass fixation related to diffuse sunlight reflected from } \\
\text { the ground }\end{array}$ & & $\mathrm{W}$ & a \\
\hline$\dot{Q}_{\text {bio,DHI,R-refl_1 }}$ & $\begin{array}{l}\text { Biomass fixation related to diffuse sunlight reflected by the } \\
\text { reactor wall }\end{array}$ & & $\mathrm{W}$ & a \\
\hline$\dot{Q}_{\text {bio,DNI }}$ & Biomass fixation related to direct sunlight & & $\mathrm{W}$ & a \\
\hline$\dot{Q}_{\text {bio,DNI,G-refl }}$ & $\begin{array}{l}\text { Biomass fixation related to direct sunlight reflected from the } \\
\text { ground }\end{array}$ & & $\mathrm{W}$ & a \\
\hline$\dot{Q}_{\text {bio,DNI,R-refl_1 }}$ & $\begin{array}{l}\text { Biomass fixation related to direct sunlight reflected by the } \\
\text { reactor wall }\end{array}$ & & $\mathrm{W}$ & a \\
\hline$\dot{Q}_{\text {convection }}$ & Heat transfer through natural air convection & & $\mathrm{W}$ & a \\
\hline$\dot{Q}_{\text {external }}$ & $\begin{array}{l}\text { Sum of all external heat fluxes affecting the top layer of the } \\
\text { ground }\end{array}$ & & $\mathrm{W}$ & a \\
\hline$\dot{Q}_{\text {ground,IR }}$ & Heat radiation from the ground & & $\mathrm{W}$ & a \\
\hline$\dot{Q}_{\text {ground,IR,R-refl }}$ & Heat radiation from the ground reflected by the panels & & $\mathrm{W}$ & a \\
\hline$\dot{Q}_{\text {ground,refl }}$ & $\begin{array}{l}\text { Reflection of direct, diffuse and thermal radiation at the } \\
\text { ground }\end{array}$ & & $\mathrm{W}$ & a \\
\hline$\dot{Q}_{\mathrm{m}}$ & Molar gas flow rate & & $\mathrm{mol} \mathrm{s}^{-1}$ & a \\
\hline$\dot{Q}_{\mathrm{DHI}}$ & Diffuse sunlight & & $\mathrm{W}$ & a \\
\hline$\dot{Q}_{\text {DHI,G-refl }}$ & Diffuse sunlight reflected by the ground & & $\mathrm{W}$ & a \\
\hline
\end{tabular}




\begin{tabular}{|c|c|c|c|c|}
\hline$\dot{Q}_{\text {DHI,R-refl }}$ & Diffuse sunlight reflected by the panels & & W & a \\
\hline$\dot{Q}_{\text {DHI,R-refl_1 }}$ & Diffuse sunlight reflected by the reactor wall & & $\mathrm{W}$ & a \\
\hline$\dot{Q}_{\text {DHI,R-refl_2 }}$ & Diffuse sunlight reflected by the culture medium & & W & a \\
\hline$\dot{Q}_{\mathrm{DNI}}$ & Direct sunlight & & $\mathrm{W}$ & a \\
\hline$\dot{Q}_{\text {DNI,G-refl }}$ & Direct sunlight reflected by the ground & & W & a \\
\hline$\dot{Q}_{\text {DNI,R-refl }}$ & Direct sunlight reflected by the panels & & W & a \\
\hline$\dot{Q}_{\text {DNI,R-refl_1 }}$ & Direct sunlight reflected by the reactor wall & & W & a \\
\hline$\dot{Q}_{\text {DNI,R-refl_2 }}$ & Direct sunlight reflected by the culture medium & & $\mathrm{W}$ & a \\
\hline$\dot{Q}_{\text {reactor,IR }}$ & Heat radiation from the reactor panels & & $\mathrm{W}$ & a \\
\hline$\dot{Q}_{\text {reactor,IR,G-refl }}$ & $\begin{array}{l}\text { Heat radiation from the reactor panels reflected by the } \\
\text { ground }\end{array}$ & & $\mathrm{W}$ & a \\
\hline$\dot{Q}_{\text {reactor,IR,R-refl }}$ & $\begin{array}{l}\text { Heat radiation from the reactor panels reflected by the } \\
\text { panels }\end{array}$ & & $\mathrm{W}$ & a \\
\hline$\dot{Q}_{\text {reactor, refl }}$ & $\begin{array}{l}\text { Reflection of direct, diffuse and thermal radiation at the } \\
\text { reactor panels }\end{array}$ & & W & a \\
\hline$R$ & Gas constant & 8.314 & $\mathrm{~J} \mathrm{~K}^{-1} \mathrm{~mol}^{-1}$ & \\
\hline$r_{0}$ & Evaporation enthalpy of water at $0{ }^{\circ} \mathrm{C}$ & $2.5 \cdot 10^{6}$ & $\mathrm{~J} \mathrm{~kg}^{-1}$ & 5 \\
\hline$R a$ & Rayleigh number & & - & a \\
\hline$\Delta t$ & Time between two simulation steps & 60 & $\mathrm{~s}$ & \\
\hline$T_{i}$ & Ground temperature between layer $i$ and $i-1\left(T_{0}=T_{\mathrm{G}}\right)$ & & $\mathrm{K}$ & a \\
\hline$T_{i}{ }^{\prime}$ & $\begin{array}{l}\text { Ground temperature of the previous time step between layer } \\
i \text { and } i-1\end{array}$ & & $\mathrm{~K}$ & a \\
\hline$T_{\mathrm{G}}$ & Ground temperature (top layer) & & $\mathrm{K}$ & a \\
\hline$T_{\mathrm{G}}$, & Ground temperature (top layer) of the previous time step & & $\mathrm{K}$ & a \\
\hline$T_{\mathrm{R}}$ & Reactor temperature & & $\mathrm{K}$ & a \\
\hline$T_{\text {air }}$ & Air temperature & dataset & $\mathrm{K}$ & 12 \\
\hline$v^{\prime}$ & Aeration rate & 0.1 & $\min ^{-1}$ & 18,19 \\
\hline$V_{\mathrm{R}}$ & Reactor volume & & $\mathrm{m}^{3}$ & a \\
\hline$x$ & Water content of air & & - & a \\
\hline$X_{\text {bio }}$ & Biomass fixation rate & 0.015 & - & b \\
\hline$\Delta x_{i}$ & $\begin{array}{l}\text { Thickness of ground layer } i \text {, see Tab. S1 for more } \\
\text { information }\end{array}$ & $\begin{array}{l}0.002 \ldots \\
8.192\end{array}$ & $\mathrm{~m}$ & b \\
\hline$x_{\mathrm{s}}$ & Water content in saturated air & & - & a \\
\hline$y$ & Distance, see Figure S2 and S7 for more information & & $\mathrm{m}$ & a \\
\hline$y^{\prime}$ & Distance, see Figure S7 for more information & & $\mathrm{m}$ & $\mathrm{a}$ \\
\hline
\end{tabular}

${ }^{a}$ parameter is dynamically computed in model

${ }^{\mathrm{b}}$ parameter is a central design input such as height of the reactor or panel distance 
Table S6. List of parameters and functions (greek characters)

\begin{tabular}{|c|c|c|c|c|}
\hline Symbol & Definition & Value & Unit & Ref. \\
\hline$\alpha$ & Solar altitude angle & & $\operatorname{deg}\left(^{\circ}\right)$ & a \\
\hline$\alpha_{\mathrm{alb}, \mathrm{G}}$ & Albedo of the ground surface & 0.3 & - & 11,24 \\
\hline$\alpha_{\mathrm{alb}, \mathrm{R}}$ & Albedo of the culture medium & 0.3 & - & 1 \\
\hline$\alpha_{\text {heat }}$ & Heat transfer coefficient & & $\mathrm{W} \mathrm{m} \mathrm{m}^{-2} \mathrm{~K}^{-1}$ & a \\
\hline$\gamma$ & Reactor orientation (aperture azimuth angle) & $0^{\circ} / 90^{\circ}$ & $\operatorname{deg}\left({ }^{\circ}\right)$ & $\mathrm{b}$ \\
\hline$\varepsilon_{\mathrm{atm}}$ & Emissivity of the atmosphere & & & a \\
\hline$\varepsilon_{\mathrm{G}}$ & Emissivity of the ground & 0.95 & - & 11 \\
\hline$\varepsilon_{\mathrm{R}}$ & Emissivity of the reactor & 0.92 & - & 5 \\
\hline$\Theta$ & Angle of incidence & & $\operatorname{deg}\left({ }^{\circ}\right)$ & a \\
\hline$\lambda_{\text {air }}$ & Thermal conductivity of air & & $\mathrm{W} \mathrm{m} \mathrm{m}^{-1} \mathrm{~K}^{-1}$ & a \\
\hline$\rho_{\mathrm{R}}$ & Density of the culture medium & 997 & $\mathrm{~kg} \mathrm{~m}^{-3}$ & 22 \\
\hline$\sigma$ & Stefan-Boltzmann constant & $5.67 \cdot 10^{-8}$ & $\mathrm{~W} \mathrm{~m} \mathrm{~m}^{-2} \mathrm{~K}^{-4}$ & 23 \\
\hline$\tau_{\text {dif,in }}$ & Transmissivity of the reactor wall for ingoing diffuse sunlight & & - & a \\
\hline$\tau_{\text {dif,out }}$ & Transmissivity of the reactor wall for outgoing diffuse sunlight & & - & a \\
\hline$\tau_{\mathrm{dir}, \text { in }}$ & Transmissivity of the reactor wall for direct sunlight & & - & a \\
\hline
\end{tabular}

a parameter is dynamically computed in model

$\mathrm{b}$ parameter is a central design input such as height of the reactor or panel distance 


\section{References}

(1) Gates, D. M.; Keegan, H. J.; Schleter, J. C.; Weidner, V. R. Spectral properties of plants. Appl. Opt. 1965, 4, 11.

(2) Stine, W. B.; Geyer, M. Power from the sun; published online at http://www.powerfromthesun.net/book.html, 2001.

(3) Slegers, P. M.; Wijffels, R. H.; van Straten, G.; van Boxtel, A. J. B. Design scenarios for flat panel photobioreactors. Appl. Energy 2011, 88, 3342-3353.

(4) Michel, H. Editorial: The nonsense of biofuels. Angewandte Chemie - International Edition. 2012, pp. 2516-2518.

(5) VDI-Wärmeatlas; Kabelac, S.; Kind, M.; Martin, H.; Mewes, D.; Schaber, K.; Stephan, P., Eds.; 11th ed.; Springer: Berlin, Heidelberg, 2013.

(6) Howell, J. R. A catalog of radiation heat transfer configuration factors. In Thermal radiation heat transfer; Howell, J. R.; Siegel, R.; Mengüç, P. M., Eds.; CRC Press Taylor \& Francis Group: New York, 2010.

(7) Brutsaert, W. On a derivable formula for long-wave radiation from clear skies. Water Resour. Res. 1975, 11, 742-744.

(8) Crawford, T. M.; Duchon, C. E. An improved parameterization for estimating effective atmospheric emissivity for use in calculating daytime downwelling longwave radiation. J. Appl. Meteorol. 1999, 38, 474-480.

(9) Wang, K.; Liang, S. Global atmospheric downward longwave radiation over land surface under all-sky conditions from 1973 to 2008. J. Geophys. Res. 2009, 114, D19101.

(10) Buck, A. L. New equations for computing vapor pressure and enhancement factor. $J$. Appl. Meteorol. 1981, 20, 1527-1532.

(11) Soil physics companion; Warrick, A. W., Ed.; 1st ed.; CRC Press: Boca Raton, 2001; Vol. 81.

(12) National Renewable Energy Laboratory (NREL). National solar radiation data base (1991 -2005 update: typical meteorological year 3)

http://rredc.nrel.gov/solar/old_data/nsrdb/ (accessed Mar 26, 2015).

(13) Henning, A.; Limberg, A. Veränderung des oberflächennahen Temperaturfeldes von Berlin durch Klimawandel und Urbanisierung - Variation of the subsoil temperature field in Berlin as a result of climate change and urbanization. Brand. Geowissenschaftliche Beiträge 2012, 19, 81-92.

(14) Schmidt, W. L.; Gosnold, W. D.; Enz, J. W. A decade of air - Ground temperature exchange from Fargo, North Dakota. Glob. Planet. Change 2001, 29, 311-325. 
(15) Heath, R. C. Basic ground-water hydrology; U.S. Geological Survey Water-Supply Paper 2220, 1983.

(16) Druecker, M.; Fan, P. Hydrology and chemistry of ground water in Puna, Hawaii. Ground Water 1976, 14, 328-338.

(17) Cengel, Y. A.; Ghajar, A. J. Numerical methods in heat conduction. In Heat and Mass Transfer: Fundamentals \& Applications; Mcgraw Hill Book Co, 2014; pp. 265-332.

(18) Sierra, E.; Acién, F. G.; Fernández, J. M.; García, J. L.; González, C.; Molina, E. Characterization of a flat plate photobioreactor for the production of microalgae. Chem. Eng. J. 2008, 138, 136-147.

(19) Rodolfi, L.; Chini Zittelli, G.; Bassi, N.; Padovani, G.; Biondi, N.; Bonini, G.; Tredici, M. R. Microalgae for oil: strain selection, induction of lipid synthesis and outdoor mass cultivation in a low-cost photobioreactor. Biotechnol. Bioeng. 2009, 102, 100-112.

(20) Christi, M. Y. Airlift bioreactors; Elsevier Science Publishers LTD: Barking, Essex, 1989.

(21) Peel, M. C.; Finlayson, B. L.; McMahon, T. A. Updated world map of the KöppenGeiger climate classification. Hydrol. Earth Syst. Sci. 2007, 11, 1633-1644.

(22) NIST Standard Reference Database Number 69. In NIST Chemistry WebBook; Linstrom, P. J.; Mallard, W. G., Eds.; National Institute of Standards and Technology.

(23) National Institute of Standards and Technology (NIST) - Physical Measurement Laboratory. Physical reference data http://physics.nist.gov/cuu/index.html (accessed Jan 15, 2016).

(24) Muneer, T. Solar radiation and daylight models; 2nd ed.; Elsevier ButterworthHeinemann: Burlington, 2004. 